\title{
High-Resolution Tropical Channel Model Simulations of Tropical Cyclone Climatology and Intraseasonal-to-Interannual Variability
}

\author{
DAN FU \\ Department of Oceanography, Texas A\&M University, College Station, Texas, and Physical Oceanography \\ Laboratory/CIMST, Ocean University of China and Qingdao National Laboratory for Marine Science \\ and Technology, Qingdao, China \\ PING CHANG \\ Department of Oceanography, and Department of Atmospheric Sciences, Texas A\&M University, College Station, \\ Texas, and Physical Oceanography Laboratory/CIMST, Ocean University of China and Qingdao National \\ Laboratory for Marine Science and Technology, Qingdao, China \\ CHRISTINA M. PATRICOLA \\ Climate and Ecosystem Sciences Division, Lawrence Berkeley National Laboratory, Berkeley, California \\ R. SARAVANAN \\ Department of Atmospheric Sciences, Texas A\&M University, College Station, Texas
}

(Manuscript received 22 February 2019, in final form 19 June 2019)

\begin{abstract}
We tailored a tropical channel configuration of the Weather Research and Forecasting (WRF) Model to study tropical cyclone (TC) activity and associated climate variabilities. This tropical channel model (TCM) covers from $30^{\circ} \mathrm{S}$ to $50^{\circ} \mathrm{N}$ at $27-\mathrm{km}$ horizontal resolution, with physics parameterizations carefully selected to achieve more realistic simulations of TCs and large-scale climate mean states. We performed 15-member ensembles of retrospective simulations from 1982 to 2016 hurricane seasons. A thorough comparison with observations demonstrates that the TCM yields significant skills in simulating TC activity climatology and variabilities in each basin, as well as TC physical structures. The correlation of the ensemble averaged accumulated cyclone energy (ACE) with observations in the western North Pacific (WNP), eastern North Pacific (ENP), and North Atlantic (NAT) is 0.80, 0.64, and 0.61, respectively, but is insignificant in the north Indian Ocean (NIO). Moreover, the TCM-simulated modulations of El Niño-Southern Oscillation (ENSO) and the Madden-Julian oscillation (MJO) on the large-scale environment and TC genesis also agree well with observations. To examine the TCM's potential for seasonal TC prediction, the model is used to forecast the 2017 and 2018 hurricane seasons, using bias-corrected sea surface temperatures (SSTs) from the CFSv2 seasonal prediction results. The TCM accurately predicts the hyperactive 2017 NAT hurricane season and near-normal WNP and ENP hurricane seasons when initialized in May. In addition, the TCM accurately predicts TC activity in the NAT and WNP during the 2018 season, but underpredicts ENP TC activity, in association with a poor ENSO forecast.
\end{abstract}

\section{Introduction}

With the rapid growth of computational resources, considerable progress has been made in advancing our climate modeling capability for tropical cyclones (TCs) by enabling climate model simulations at TC-permitting

Corresponding author: Dan Fu, fudan1991@tamu.edu horizontal resolution $(\leq 50 \mathrm{~km})$ (Zhao et al. 2009; Chen and Lin 2013; Murakami et al. 2012; Bacmeister et al. 2014; Walsh et al. 2015). Simulations of TCs have been steadily improving, partly because of the better capability of representing TCs due to the enhanced resolution (Shaevitz et al. 2014; Wehner et al. 2014) and partly because of the improved representation of linkages between TC activity and the large-scale climate modes that 
strongly modulate environmental TC favorability, such as the Madden-Julian oscillation (MJO), boreal summer intraseasonal oscillation (BSISO), El Niño-Southern Oscillation (ENSO), and Atlantic meridional mode (AMM) (Satoh et al. 2012; Vecchi et al. 2014; Murakami et al. 2015; Xiang et al. 2015; Patricola et al. 2014, 2016, 2018; Vitart et al. 2017; Nakano et al. 2015). These recent advances build confidence that climate models are more readily applicable than before for understanding TC variability and change, for making seasonal predictions, and even future climate projections of TC activity.

Compared to global climate models, regional climate models (RCMs) with a tropical channel configuration offer advantages of being more computationally efficient and more flexible in choice of physics parameterizations, and thus are a viable alternative for studying TCs and their relationships to various modes of tropical climate variability (Leung et al. 2006; Holland et al. 2006; Ray et al. 2009, 2012). With a zonal periodic configuration, the tropical channel model (TCM) is continuous in the east-west direction and thereby allows free circumnavigation of tropical modes. Patricola et al. $(2016,2018)$ conducted TC simulations using a $27-\mathrm{km}$ resolution TCM to elucidate how the two types of El Niño have distinct influences on western North Pacific (WNP) and North Atlantic (NAT) TC activity. The same model forced with prescribed SST patterns characteristic of the AMM was also applied to study the remote influence of Atlantic SSTs on eastern North Pacific (ENP) TC activity (Patricola et al. 2017).

Although the TC-permitting TCM used by Patricola et al. $(2016,2017,2018)$ has demonstrated some success in revealing teleconnections between tropical SST climate variability and TC activity in different ocean basins, these simulations have also shown some biases in both the large-scale tropical circulation and the spatial distributions of TCs. For example, the simulated ENP TCs are predominantly confined to the eastern margin of the ENP and their westward propagations are not captured well. The impact of these model biases on simulated TC variability has not been fully addressed. In addition, previous studies primarily focused on how modes of interannual climate variability modulate TC activity in idealized simulations. However, the extent to which subseasonal TC variability and its relationship to modes of intraseasonal variability, such as the MJO, can be simulated by SST-forced TCM simulations has not been thoroughly investigated. Therefore, it remains unknown whether the TCM can be used to study TC variability and predictability on subseasonal-to-seasonal (S2S) time scales (Vitart et al. 2017).

Hence, this study builds on the previous work on the TCM by Patricola et al. $(2016,2017,2018)$ and further improves its configuration for realistically simulating TC variability on S2S time scales. By conducting an ensemble of retrospective seasonal hindcast simulations forced with high-resolution daily SSTs, we evaluate the skill of the improved TCM in hindcasting TC variability. In addition, we perform a set of TC seasonal prediction experiments for the 2017 and 2018 hurricane seasons using the TCM to examine potential skills of the model for TC seasonal prediction. Detailed descriptions of the TCM formulation and the data used for model input are given in section 2. Section 3 evaluates the simulated TC climatology, its spatial structures, and large-scale environments for the period 1982-2016. Intraseasonal-tointerannual variability of TCs is assessed in section 4. A set of experimental seasonal forecasts for 2017 and 2018 hurricane seasons is presented in section 5. Section 6 provides a summary of the results and discussion.

\section{Model, data, and methodology}

\section{a. Model description}

The Advanced Research version of the Weather Research and Forecasting (WRF) Model (WRF-ARW) is a fully compressible nonhydrostatic community atmospheric model with a terrain following vertical coordinate (Skamarock et al. 2008). Following Patricola et al. (2016, 2017, 2018), WRF-ARW (hereafter WRF) is configured with a periodic zonal boundary condition, northern and southern lateral boundaries at $30^{\circ} \mathrm{S}$ and $50^{\circ} \mathrm{N}$, TC-permitting $27-\mathrm{km}$ horizontal resolution, and 32 vertical layers from the surface to $50 \mathrm{hPa}$ (Fig. 1). The integration time step is set at $60 \mathrm{~s}$.

Previous studies have demonstrated the importance of model physics parameterizations in TC and regional climate simulations ( $\mathrm{Hu}$ et al. 2010; Evans et al. 2012; Nasrollahi et al. 2012; Crétat et al. 2012; Bruyère et al. 2017). To reduce the biases present in earlier TCM configurations (Patricola et al. 2016, 2017, 2018) and to tailor the TCM for realistically simulating the TC climatology and associated climate variability, we carefully optimized the model physics schemes before performing the suites of model experiments (see details in the appendix). The selected physics parameterizations are the Purdue-Lin microphysics scheme (Lin et al. 1983), the Dudhia (1989) shortwave radiation scheme, the Rapid Radiative Transfer Model (RRTM; Mlawer et al. 1997) longwave radiation scheme, the MM5 MoninObukhov surface layer scheme (Monin and Obukhov 1954), the four-layer Noah land surface model (Chen and Dudhia 2001), and the Yonsei University planetary boundary layer (PBL) scheme (Hong et al. 2006). The new simplified Arakawa-Schubert (NSAS) cumulus 


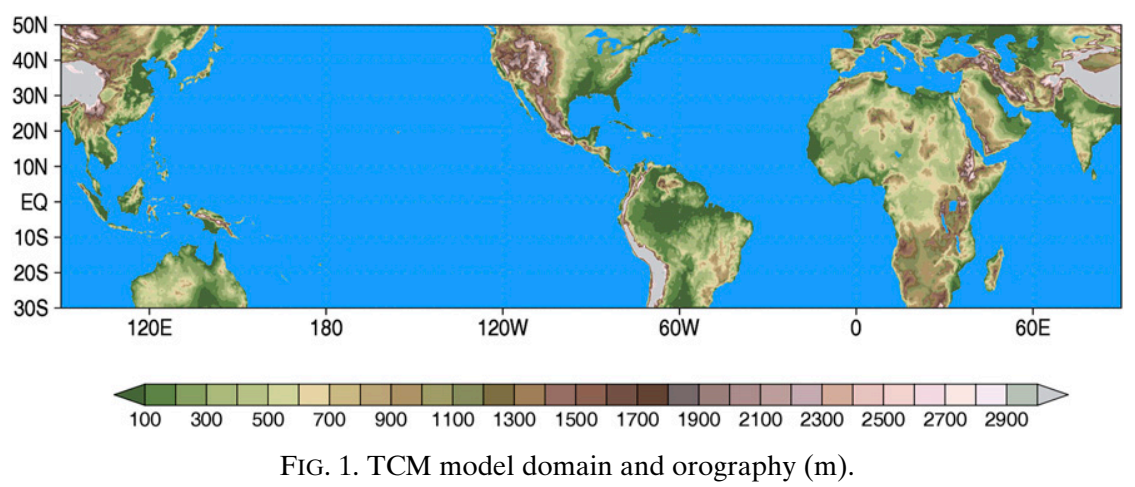

scheme (Han and Pan 2011) is employed to parameterize atmospheric shallow and deep convection. Across the air-sea interface, the exchange coefficients of momentum and enthalpy (sensible and latent heat) fluxes are determined by the Donelan et al. (2004) and Garratt (1992) formulations. The parameterization of subgridscale orographic gravity wave drag processes was not employed in the simulations. All of the simulations are free running, without nudging or any other data assimilation techniques. Model historical outputs were saved at 6-hourly intervals.

To provide a comprehensive assessment of the simulated TC climatology and interannual variability, we conducted a 15-member ensemble of seasonal hindcast simulations for 35 boreal summer seasons from 1982 to 2016. The large ensemble size is essential to ensure a clean separation between model's internal variability and forced variability. The initial and lateral boundary conditions and SST forcing are prescribed using the 6hourly National Centers for Environmental Prediction (NCEP) Climate Forecast System Reanalysis (CFSR; 1979-2010; Saha et al. 2010) and its extension, the Climate Forecast System version 2 operational analysis (CFSv2; April 2011 onward; Saha et al. 2014). SSTs in the CFSR and CFSv2 are strongly nudged to the National Climatic Data Center (NCDC) daily SST analysis, and therefore largely consistent with satellite observations (Saha et al. 2010). The 15 ensemble members for each season were generated by initializing the model with different atmospheric states. Specifically, the 15 hindcast runs in each season were started at different dates from 22 April to 6 May. Each run covers the main hurricane season in the Northern Hemisphere from June to November and ends on 1 December, with output in May disregarded as model spinup. Although intense TCs in the WNP and north Indian Ocean (NIO) are called typhoons and severe cyclonic storms, for simplicity we refer to all of them as hurricanes, using the definition of lifetime maximum intensity greater than $32.9 \mathrm{~m} \mathrm{~s}^{-1}$. We note that 10 of the 15 ensemble members were performed using WRF version 3.5.1 on the Lonestar5 system of Texas Advanced Computer Center (TACC), while the remaining five were conducted using WRF version 3.6.1 on TACC's Stampede2 system. To keep the consistency of the different model versions, we turned off the newly implemented lake physics and scale-aware NSAS deep convection in WRF version 3.6.1, and used exactly the same physics schemes. Test runs were conducted to compare the two versions of the model and nearly identical results were obtained, indicating that the simulations are insensitive to the version of WRF.

The TC detection and tracking algorithm is described in the appendix. To better illustrate the spatial distribution of TCs, we define the TC track density as the accumulated number of TC central locations within each $2^{\circ} \times 2^{\circ}$ grid box at a 6-h interval for each season. The total count of TCs within each box is defined as the track density. The first position that each $\mathrm{TC}$ reaches $17.5 \mathrm{~m} \mathrm{~s}^{-1}$ is defined as the genesis position; analogously, we define genesis density as the accumulation of the genesis positions at each grid box. The density fields are then smoothened with a 9-point weighted moving average.

\section{b. Observational datasets}

To evaluate the TC characteristics and activity simulated by the TCM, we used the observed TC best track data from the International Best Track Archive for Climate Stewardship (IBTrACS; Knapp et al. 2010) dataset v03r10. The IBTrACS data consist of best-track data from all the Regional Specialized Meteorological Centers and provides historical TC information for 6-hourly TC center positions, maximum 10-m wind speed (WSPD), minimum sea level pressure (SLP), and sizes of $\mathrm{TC}$, in terms of wind radii, if applicable. We only used TCs with tropical storm strength or greater (i.e., maximum lifetime 1-min sustained 10-m WSPD stronger than $17.5 \mathrm{~m} \mathrm{~s}^{-1}$ ) during June to November 1982-2016 for an equal comparison with the TCM. 
(a) TRMM

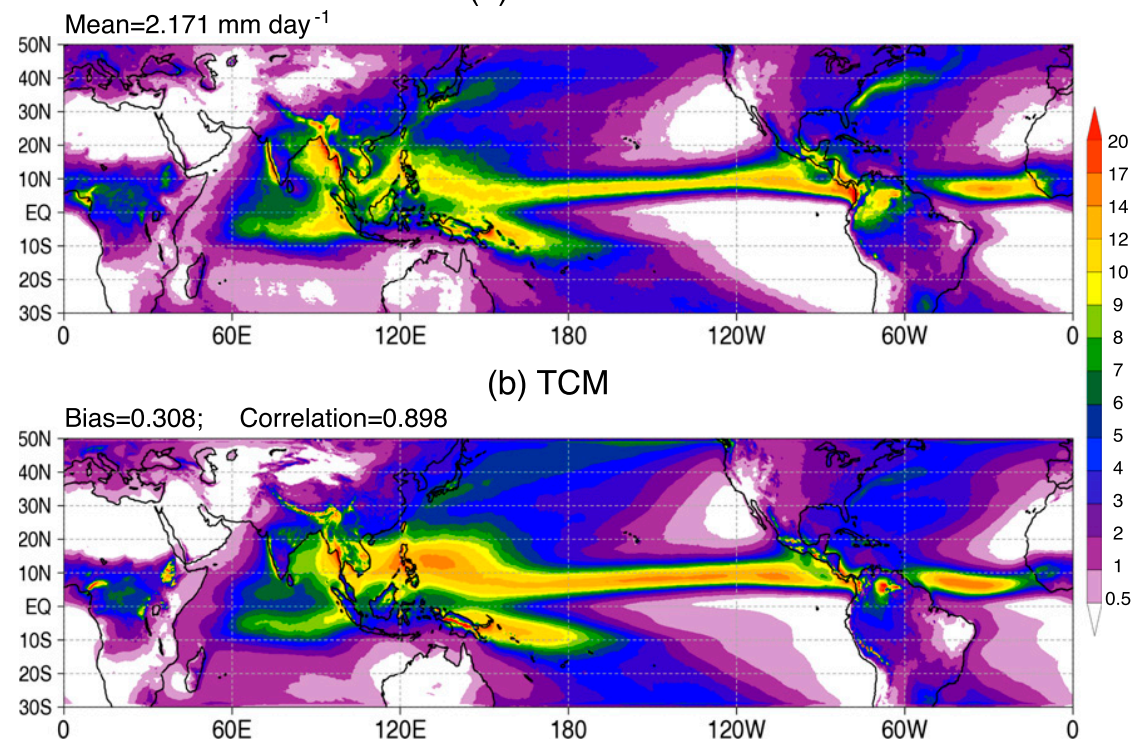

(c) PDFs of tropical precipitation

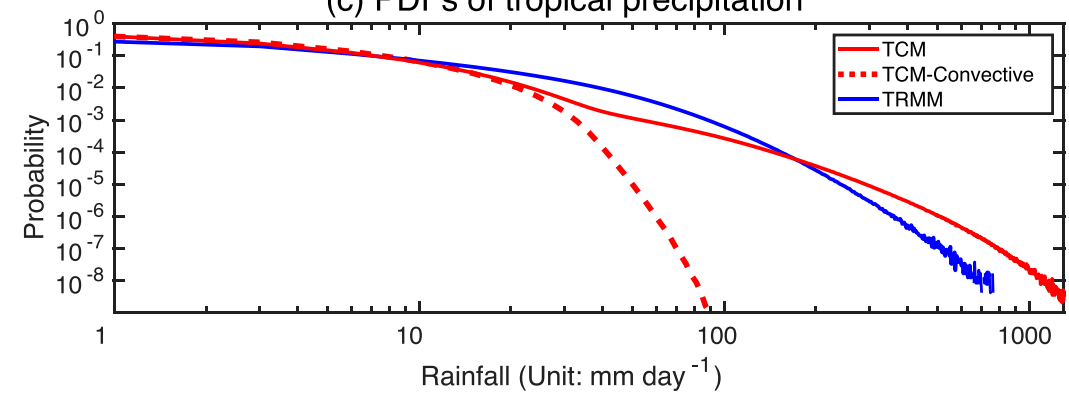

FIG. 2. 1998-2016 June-November (JJASON) averaged precipitation rates (mm day ${ }^{-1}$ ) from (a) TRMM observation and (b) TCM hindcast simulation ensemble mean. (c) Probability density functions (PDFs; \%) of tropical precipitation $\left(20^{\circ} \mathrm{S}-20^{\circ} \mathrm{N}\right)$ derived from daily accumulated values during the same period. Red solid line shows the results for TCM total rainfall (sum of convective and nonconvective precipitation), red dashed line for precipitation produced by cumulus parameterization, and blue line for TRMM. PDFs in TCM are calculated based on each individual ensemble member, rather than the ensemble mean. Probabilities are calculated using bins of $3 \mathrm{~mm}_{\text {day }}{ }^{-1}$.

To assess the simulated TC structures with observations, the Global Precipitation Measurement (GPM) mission (Huffman et al. 2015a) and the fifth generation of the European Centre of Medium-Range Weather Forecasts (ECMWF) reanalysis (ERA5; http://apps.ecmwf.int/ data-catalogues/era5/?class =ea) were used to derive composites of observed TC-induced precipitation (see details in the appendix). For evaluation of the simulated climatological mean states of large-scale atmospheric variables, we used the Tropical Rainfall Measuring Mission (TRMM) multisatellite precipitation analysis (Huffman et al. 2007) for the period 1998-2016, the ERA-Interim reanalysis (Dee et al.2011) for the period 1982-2016, and the Objectively Analyzed Air-Sea Fluxes (OAFlux; Yu et al. 2008) surface turbulent heat flux product for the period 1982-2016. To compare simulated intraseasonal variations with observations, we used daily averaged outgoing longwave radiation (OLR) data from the Advanced Very High Resolution Radiometer (AVHRR; Liebmann and Smith 1996) and zonal winds at 200 and $850 \mathrm{hPa}$ from the National Centers for Environmental Prediction (NCEP)National Center for Atmospheric Research (NCAR) reanalysis (Kalnay et al. 1996) for the period 1982-2016.

\section{Tropical cyclone climatology}

\section{a. Large-scale environment mean state}

Figures $2 \mathrm{a}$ and $2 \mathrm{~b}$ compare the seasonal mean precipitation rate from the TCM simulation ensemble mean 
with TRMM 3B42 satellite observations. Note that TRMM has a horizontal resolution of $0.25^{\circ} \times 0.25^{\circ}$, which is comparable to the TCM horizontal resolution of $27 \mathrm{~km}$, so it is fair to make a direct comparison. The pattern correlation and bias are presented at the top of Fig. 2b. In general, the model reproduces the observed precipitation pattern with a relatively small bias of $0.308 \mathrm{~mm} \mathrm{day}^{-1}$ and a high spatial correlation of 0.9 . The model also reproduces the observed tropical precipitation distributions with high fidelity, showing a broad agreement of the mean location and strength of the intertropical convergence zone (ITCZ) between the observations and the simulation, especially over the eastern portion of ENP, where many general circulation models commonly overestimate the rainfall (Chen and Lin 2013; Bacmeister et al. 2014).

The biggest precipitation discrepancies are located over the WNP warm pool and western boundary current regions in the Pacific and Atlantic, which may imply potential inherent biases in the cumulus scheme over warm waters. In addition, Fig. $2 c$ displays the probability density functions (PDFs) of daily-accumulated precipitation in the tropics $\left(20^{\circ} \mathrm{S}-20^{\circ} \mathrm{N}\right)$ from the TCM hindcast simulations and TRMM 3B42. The simulated frequency of weak-to-moderate precipitation (lighter than $20 \mathrm{~mm} \mathrm{day}{ }^{-1}$ ) is remarkably consistent with the observed (Fig. 2c). However, there are some major differences between observed and simulated PDFs in heavy (between 20 and $200 \mathrm{~mm} \mathrm{day}^{-1}$ ) and extreme (more than $200 \mathrm{~mm} \mathrm{day}^{-1}$ ) precipitation rates. The model underestimates the former, but overestimates the latter. Note that previous studies have indicated that the TRMM product underestimates precipitation in heavy rainfall regimes (Bowman et al. 2003; Berg et al. 2006; Liao and Meneghini 2009), suggesting that the model bias may be less than what is shown here. It is evident that almost all of the precipitation with rates larger than $50 \mathrm{~mm} \mathrm{day}{ }^{-1}$ is produced by the model's large-scale condensation routines that are related to the microphysics scheme. We speculate that the model biases in heavy and extreme precipitation regimes may originate from flaws associated with the microphysics parameterization, and suggest additional research to minimize this discrepancy.

Other key simulation parameters for climate mean state are concisely summarized in a Taylor diagram (Taylor 2001; Fig. 3). The variables that are most relevant to TC environment conditions, such as zonal wind at 200 and $850 \mathrm{hPa}$ (U200 and U850), vertical wind shear between 200 and $850 \mathrm{hPa}$ (VWS), and sea level pressure, are reasonably well simulated by TCM, with pattern correlations near or above 0.95 , and normalized standard deviation close to 1.0. To avoid

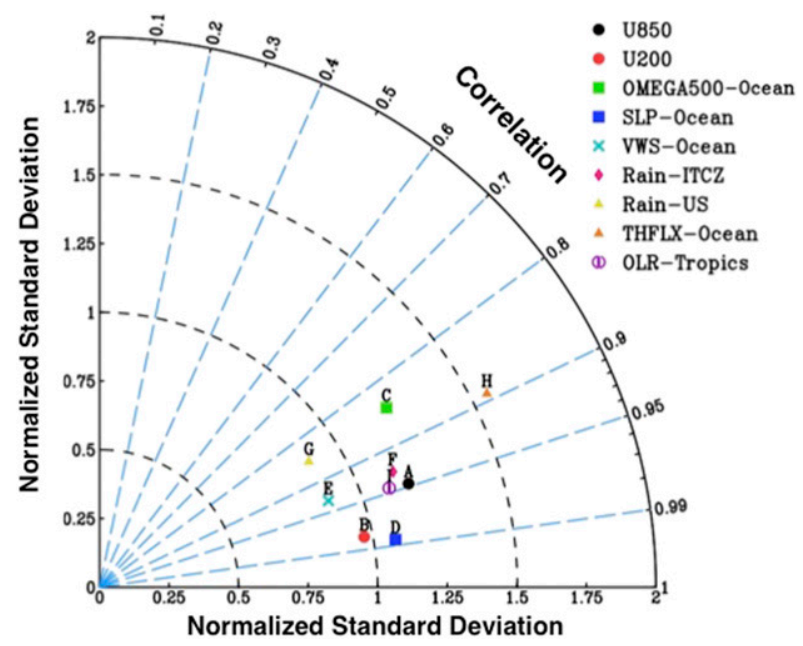

FIG. 3. Taylor diagram (see text) for several key parameters of climate mean state. Correlations and normalized standard deviations are calculated using seasonal means of 1982-2016 JJASON. The observational data are interpolated to TCM grid for fair comparison purpose.

the complication of orographic effects that are not well resolved in $0.75^{\circ}$ resolution atmospheric reanalysis, VWS and SLP are only averaged over ocean. The simulated 500 -hPa vertical velocity over ocean (OMEGA500-Ocean) has the lowest correlation with ERA-interim $(r=0.84)$, whereas simulated OLR within the tropics has relatively better agreement with satellite retrieval $(r=0.95)$. This may partly be due to the lack of finescale representation of convective systems in the ERA-Interim. The turbulent heat flux (total of latent and sensible heat flux) over ocean shows the largest difference in the normalized standard deviation but has a pattern correlation of about 0.90 . Given that the OAFlux is subjectively calculated based on bulk formulas, the reliability of these estimates may be less than other quantities. Unfortunately, no other high-resolution in situ flux observations are currently available to validate the simulated fluxes. The uncertainties in parameterizing surface flux still remain an unmet challenge to our ability to simulate climate mean state and the structure and intensity of TCs.

Figure 4 shows the June-November seasonal averaged value of the genesis potential index (GPI; Emanuel and Nolan 2004), which represents the favorability of the environment for TCs. A larger GPI indicates a greater possibility of TC genesis under given large-scale environments. Again, the pattern of GPI derived from the TCM simulation shows remarkable agreement with that from the ERA-Interim, with a spatial correlation greater than 0.95 and a bias around -0.1 . This high correlation value combined with the aforementioned 
(a) ERA-interim

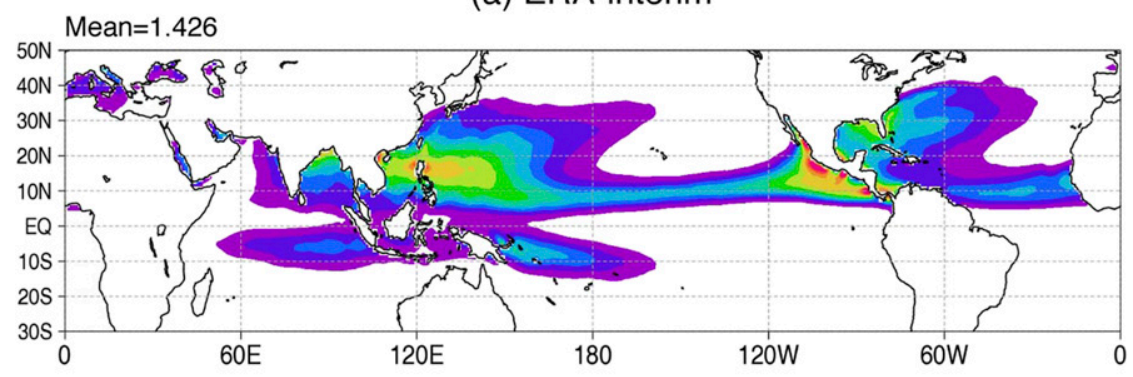

(b) TCM

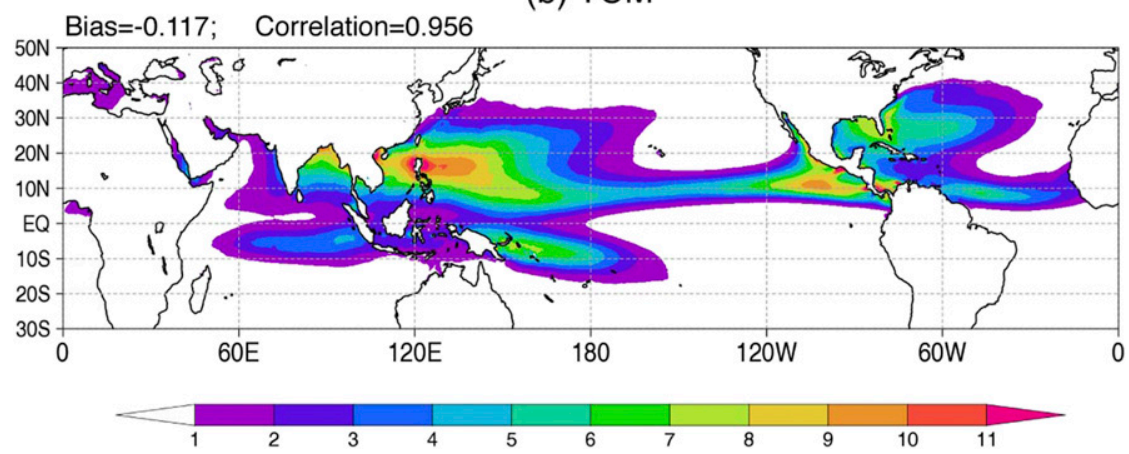

FIG. 4. 1982-2016 JJASON averaged GPI (unitless) from (a) ERA-Interim reanalysis and (b) TCM hindcast simulation ensemble mean. Larger values indicate more favorable environmental conditions for TC genesis.

fidelity in simulating large-scale atmospheric circulation features build our confidence in results based on the TC simulations.

\section{b. Tropical cyclone intensity and spatial distribution}

Figures $5 \mathrm{a}$ and $5 \mathrm{~b}$ compare observed and simulated spatial distributions of TC tracks for the period 19822016 June-November. For clarity, we only plot the simulated tracks from three ensemble members, while the seasonal mean numbers listed in the panel are based on the 15-member ensemble mean. Compared with the observations, the TCM overall reproduces realistic distributions of TC tracks, with the most concentrated TC activity over the WNP, followed by the ENP and NAT. The simulated seasonal mean Northern Hemisphere total number of TC $\left(51.3 \mathrm{TCs} \mathrm{yr}^{-1}\right)$ is very close to the observation (52.1 $\left.\mathrm{TCs} \mathrm{yr}^{-1}\right)$. Although the simulated TC tracks show quite similar spatial distributions, the maximum lifetime TC intensity is considerably underestimated by the TCM. We will address this issue later in this section. Figures $5 \mathrm{c}$ and $5 \mathrm{~d}$ assess the observed and simulated TC genesis locations. Consistent with observations, simulated TC genesis locations are geographically very concentrated in the WNP and ENP but scattered in the NAT. In the WNP and NIO, the TC occurrences in the model are mostly located within the same regions as those in the observations, but are apparently too active. The TCM also simulates more frequent TCs in the central Pacific, but dormant activity in the eastern portion of the ENP. The simulated TC genesis events within Gulf of Mexico (GoM) are also less frequent than observed, while more TCs are simulated in the midlatitudes of the central Atlantic, which is consistent with the overestimated precipitation and GPI over the same region in the model (Figs. $2 b$ and $4 b$ ).

\section{c. Tropical cyclone seasonal variation}

Figure 6 compares seasonal variations of hurricane and TC occurrence frequencies between observations and TCM simulations. In the NAT, the TCM reproduces the observed peak of TC activity with the most active occurrences of hurricane and TC in August-October, while the simulated WNP TC activity appears to be strongest during July-September, slightly earlier than the observed peak of August-October. In the ENP and NIO, the regions where the TCM shows the largest inconsistency with observed mean TC activity, the TCM also displays a bias in the seasonal cycle. In the latter part of the season, the TCM overestimates the ENP TC activity, especially the frequency of hurricane occurrence in September-October. In contrast to the ENP, 
(a) IBTrACS tracks

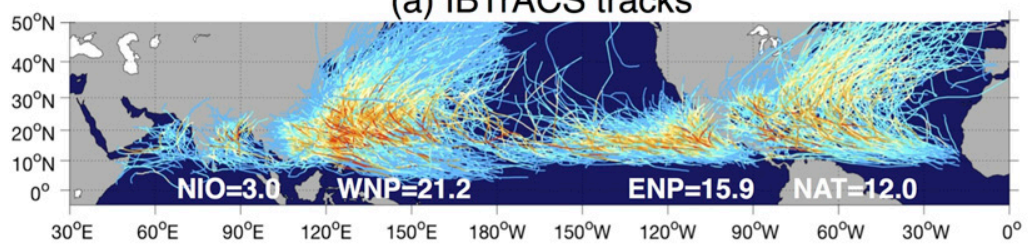

(b) TCM tracks

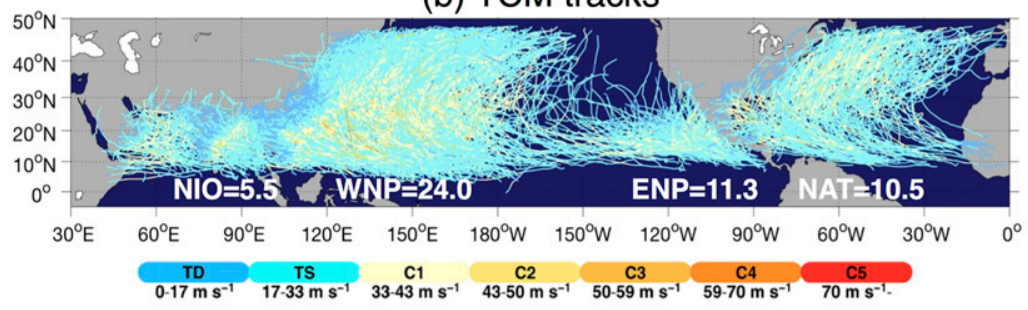

(c) IBTrACS gensis density

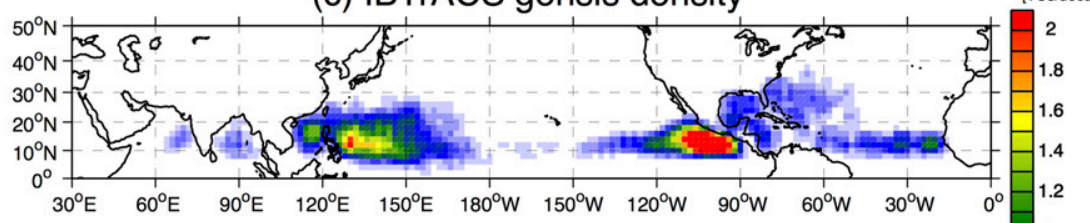

(d) TCM gensis density

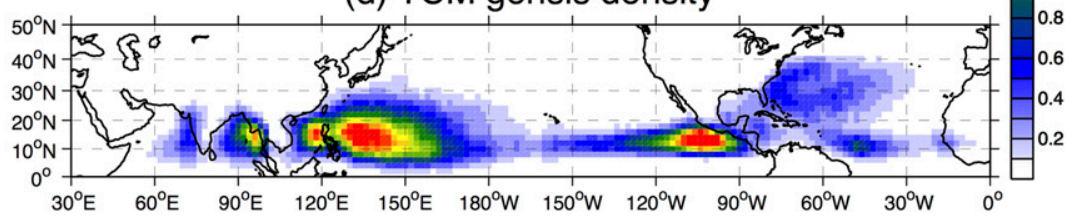

(e) TCM - IBTrACS

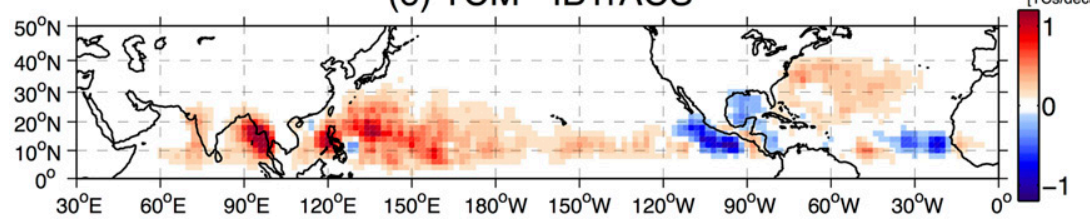

FIG. 5. Distribution of TC tracks during 1982-2016 seasons from (a) observation and (b) TCM hindcast simulation. The numbers for each basin show the seasonal mean value of TC numbers. TC tracks are colored based on the Saffir-Simpson hurricane wind scale, which are tropical depression (TD), tropical storm (TS), and hurricane categories 1-5 (C1-C5), respectively. For clarity, only simulated TCs from the first three ensemble members are plotted. Also shown are TC genesis density (number of TC records per decade) from (c) observation and (d) TCM simulation, and (e) their difference.

the TCM simulated NIO TC activity is too weak in November but relative stronger during the most of summer monsoon season (July-September). Note that although not as strong as the Indian monsoon, the ENP is also characterized by the North American monsoon system, and TC activity in the ENP and NIO is closely linked with the monsoon dynamics (e.g., vertical wind shear in the monsoon regions and locations of the monsoon trough). The results here suggest that although the mean values of precipitation in the ENP and NIO are well simulated by the TCM, the simulation of North
American and Indian monsoons, especially the onset and dissipation times, may be biased.

\section{d. Tropical cyclone structure}

We next examine the characteristics and structure of TCs separated by ocean basin, starting with the NAT (Fig. 7). The strongest lifetime maximum intensity of simulated NAT TCs is primarily hurricane category 2 , and occasionally category 3 in terms of maximum WSPD, and category 4 in terms of minimum SLP (Fig. 7a). Consistent with the bias in TC maximum intensity, the probability of 
(a) North Atlantic

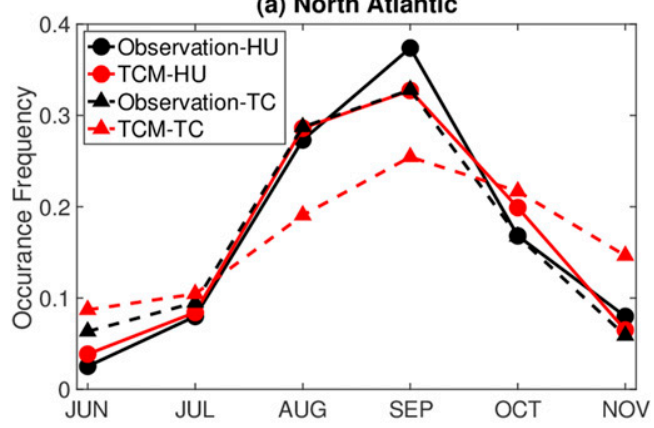

(c) Eastern North Pacific

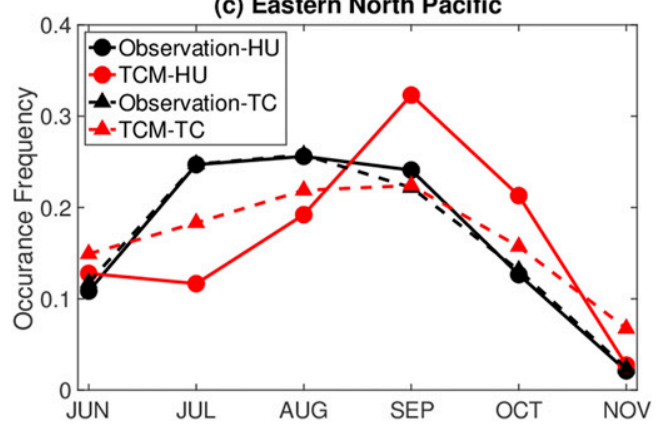

(b) Western North Pacific

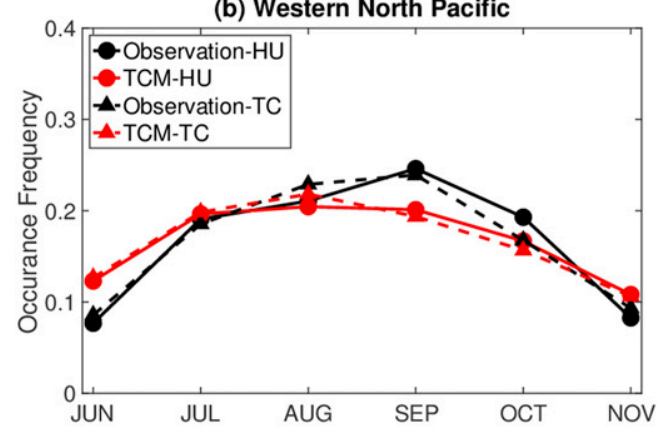

(d) North Indian Ocean

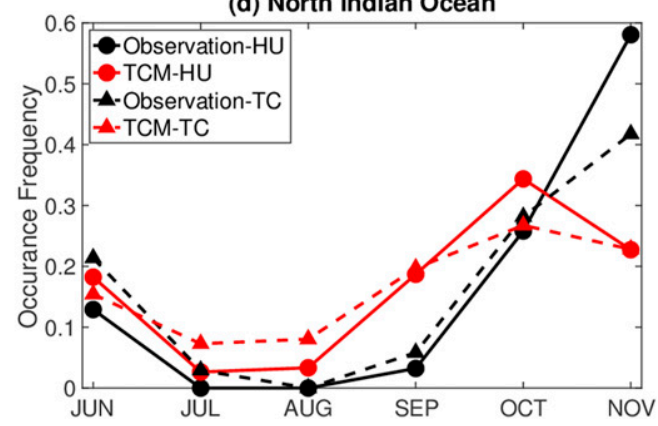

FIG. 6. PDFs of monthly variations of TC activity in (a) NAT, (b) WNP, (c) ENP, and (d) NIO. Solid (dashed) black curves with circles (triangles) denote the frequency of hurricanes (all TCs) occurrences in the observation. Red curves indicate the results from the TCM hindcast simulation.

hurricane-scaled winds is significantly underestimated by the TCM (Fig. 7b), indicating the model's deficiency in simulating intense hurricanes. However, the composite of simulated NAT hurricanes shows four geographical quadrant-averaged 34,50 , and $64 \mathrm{kt}\left(1 \mathrm{kt} \approx 0.5144 \mathrm{~m} \mathrm{~s}^{-1}\right)$ wind radii of $194.05,104.08$, and $52.54 \mathrm{~km}$, which are $82.7 \%, 90.0 \%$, and $92.7 \%$ of the observed values of $234.60,115.56$, and $56.66 \mathrm{~km}$, respectively (Figs. 7c,d). This broad agreement in the spatial attributes of the hurricane wind field indicates that although the TCM fails to generate strong hurricanes, the spatial structure of simulated TCs is reasonably well represented given the limitation on the model horizontal resolution (Davis 2018). The hurricane-induced precipitation in the model is mainly confined to the downshear left side of the environmental vertical wind shear where the environmental shear conflicts with TC primary circulation. This result is consistent with previous studies (Lonfat et al. 2004; Chen et al. 2006) and also confirmed by the Global Precipitation Measurement (GPM) precipitation datasets (Fig. 7c; see details in the appendix). The model simulates more intense precipitation near TC inner core area, which is consistent with Nasrollahi et al. (2012), who reported commonly overestimated hurricane precipitation when using the Purdue-Lin microphysics scheme. This simulated excessive hurricane precipitation may also contribute substantially to the PDFs bias in extreme precipitation regime (Fig. 2c). Figures $7 \mathrm{e}$ and $7 \mathrm{f}$ are the composites of azimuthal averaged hurricane vertical cross section of dynamic and thermodynamic fields in the model. Even with the relatively coarse resolution compared to the TC spatial scale, the model shows ability to simulate the significant hurricane warm core, tilted eyewall structures, and upper-level radiative cooling that are observed in mature hurricanes.

Figures 8 and 9 represent similar analyses for the simulated TC characteristics in the WNP and ENP, respectively. The NIO results are not shown here due to the small sample size. Comparing with the NAT, simulated TCs in the WNP typically have stronger maximum intensities and are commonly larger in size, consistent with observations. In contrast, the simulated ENP TCs are climatologically weaker and smaller compared with the NAT TCs. Interestingly, although the simulated TC lifetime intensities vary with ocean basins, the corresponding regressions between minimum SLP and maximum WSPD of TCs remain almost unchanged. This result may suggest that the underlying dynamics of TC intensification in the model are similar among different basins. Note that the observed TCs also show consistent differences in sizes among different basins. Similar to the simulated TCs, larger TCs tend to occur in the WNP and smaller TCs occur in the ENP and NAT. Since the TCM has a uniform 27-km horizontal resolution, the model may show more difficulties in simulating strong TCs in NAT and ENP TCs than in WNP, as 
(a) NAT TC Wind-Pressure Relationship

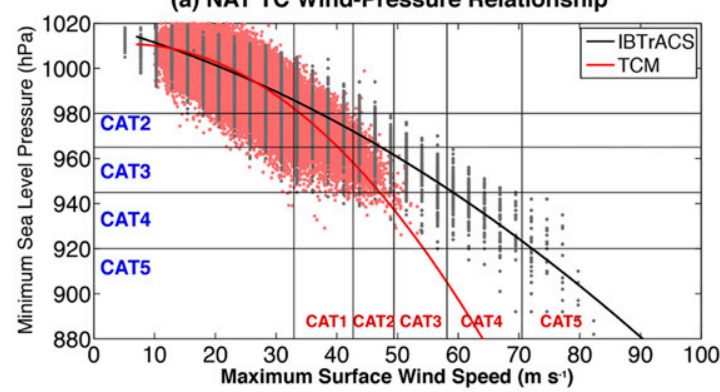

(b) NAT PDFs of TC Wind Speed $\left(\mathrm{m} \mathrm{s}^{-1}\right)$

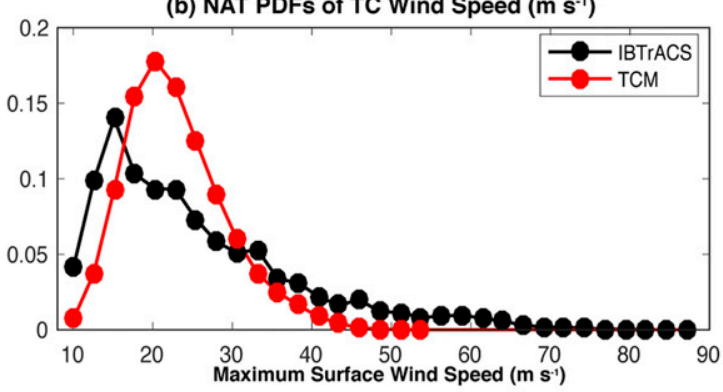

(c) GPM_HQ NAT

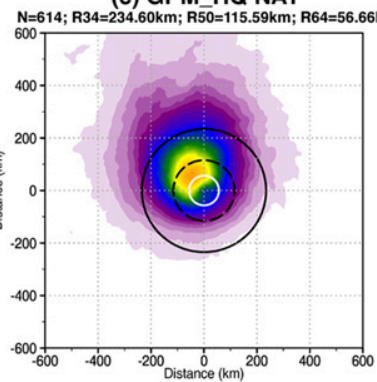

(e) TMP anomaly \& WSPD

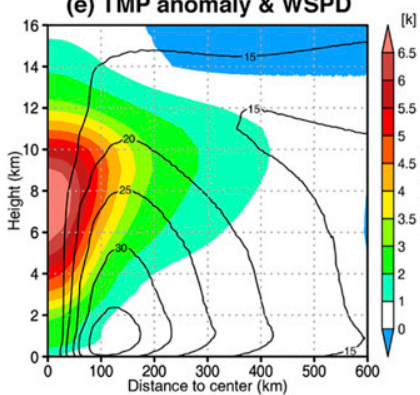

(d) TCM ENP

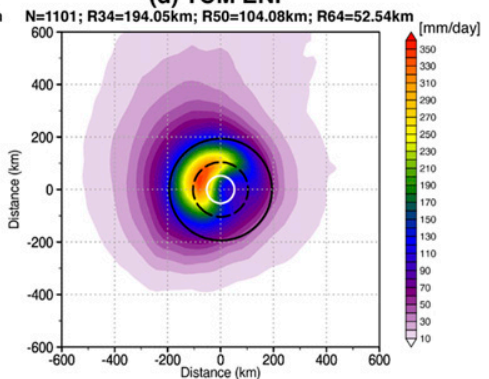

(f) Diabatic heating \& Radial Vel.

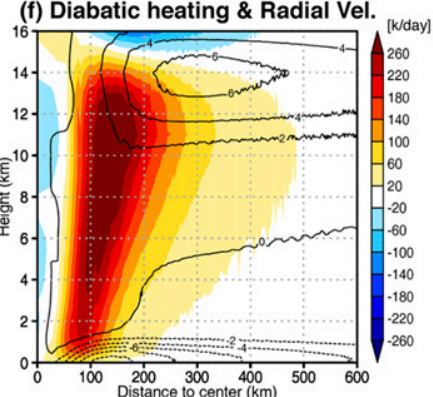

FIG. 7. (a) NAT TCs maximum wind speed (WSPD; $\mathrm{m} \mathrm{s}^{-1}$ ) and minimum SLP (hPa) relationship derived from TCM (red), and observation (black). The red (black) curves are the regressions line based on least squares quadratic best fit. Hurricane categories are listed in red (blue) based on WSPD (SLP) criteria. (b) PDFs (\%) of 6-hourly TC maximum WSPD that aggregated into 5-kt bins. Composite structures of NAT TC precipitation rate $\left(\mathrm{mm} \mathrm{day}^{-1}\right)$ from (c) GPM satellite retrieval and (d) TCM simulation. The snapshots of each precipitation were first rotated along the ambient vertical wind shear, with the shear vector pointing to the top, and then made the composites (see appendix $\mathrm{C}$ and Fig. C1 for details). The solid black, dashed black, and solid white circles indicate the quadrants-averaged 34-, 50-, and 64-kt wind radii from observation and TCM, respectively. The values listed on the panels are sample sizes, and averaged TC wind radii (km). Azimuthal mean distance-height cross sections of (e) temperature anomaly $(\mathrm{K})$ and wind speed $\left(\mathrm{m} \mathrm{s}^{-1}\right)$ and (f) diabatic heating $\left(\mathrm{k} \mathrm{day}^{-1}\right)$ and radial velocity $\left(\mathrm{m} \mathrm{s}^{-1}\right)$. Radial velocity is positive outward. All composites are made for TCs of hurricane category or greater.

shown in Figs. 7a, 8a, and 9a, simply because the uniform grid spacing is less effective in representing TC inner core dynamics in the NAT and ENP than in the WNP TCs.

Figure 10 further shows one of the strongest hurricanes that simulated by TCM. This sample hurricane snapshot has the minimum SLP of $910.34 \mathrm{hPa}$ and maximum WSPD of $61.52 \mathrm{~m} \mathrm{~s}^{-1}$, which reaches to category 4 intensity. A clearly discernible eye can be recognized from OLR snapshot, with most excessive rainfall and deepest convection surrounding the center. However, the simulated hurricane surface wind speed maximizes at a distance of about $100 \mathrm{~km}$ from the center, indicating a larger radius of maximum winds than the mean of observed Atlantic hurricanes from the satellite-based estimation of $64.6 \mathrm{~km}$ [Table 2 of Kimball and Mulekar (2004)].

\section{Intraseasonal-to-interannual tropical cyclone variability}

\section{a. Interannual variability}

Table 1 summarizes the correlations of number of tropical cyclones, hurricanes, and accumulated cyclone energy (ACE; Bell et al. 2000) between the simulations and observations during the 1982-2016 period. Since 15 ensemble members are available for each season, the ensemble mean and the maximum and minimum correlations among the different ensemble members are listed individually. Overall, the TCM yields significant correlations between simulated and observed TC variability in all basins except the NIO. The correlation value of $\mathrm{ACE}$ is 0.80 in the WNP, with maximum and minimum values of 0.86 and 0.51 , respectively. For the number of TCs and hurricanes, the correlation drops to 0.48 and 0.64 using the ensemble mean, but is still statistically significant at the $99 \%$ confidence level. Given that ACE is determined by TC counts, as well as the intensity and duration of each storm, we conjecture that interannual variability of large-scale key factors that control TC activity is more effective in modulating TC numbers than influencing TC intensity and duration over the WNP.

The correlations in the ENP and NAT are generally lower than that in the WNP, but still pass the two-sided Student's $t$ test at $99 \%$ confidence level. Interestingly, the differences in correlation of ACE and TC counts are 
(a) WNP TC Wind-Pressure Relationship

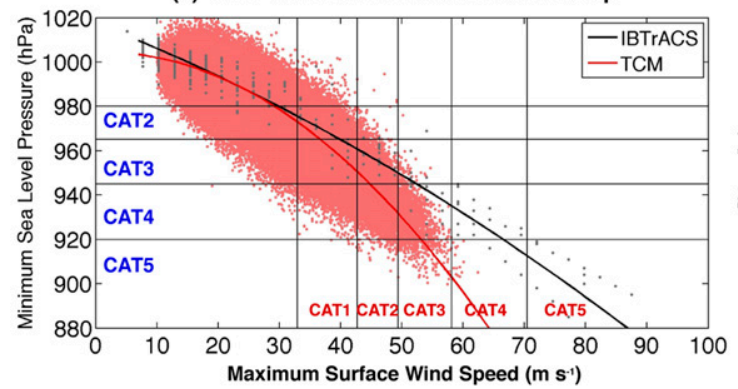

(b) WNP PDFs of TC Maximum Wind Speed $\left(\mathrm{m} \mathrm{s}^{-1}\right)$

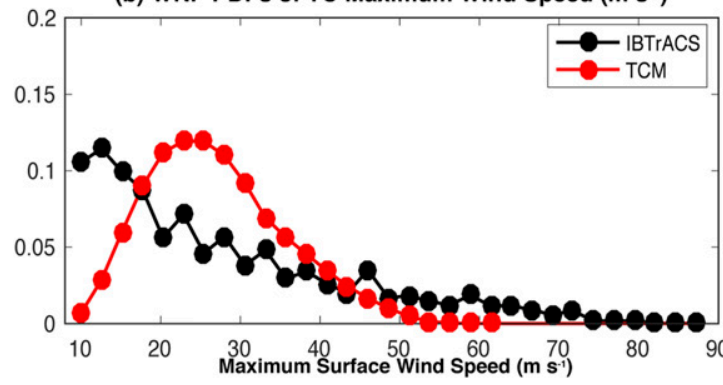

(a) GPM_HQ WNP

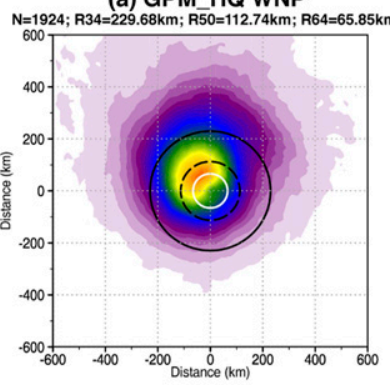

(e) TMP anomaly \& WSPD

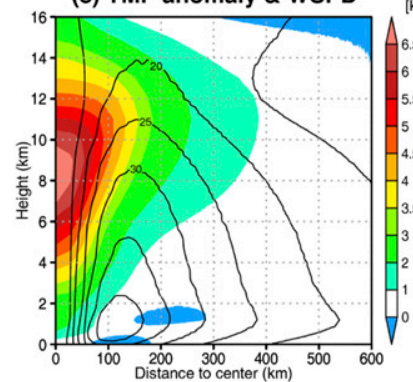

(b) TCM WNP

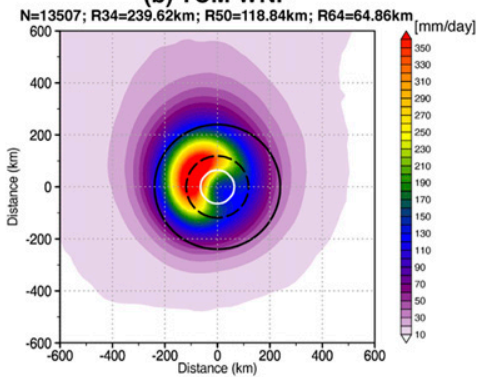

(f) Diabatic heating \& Radial Vel.

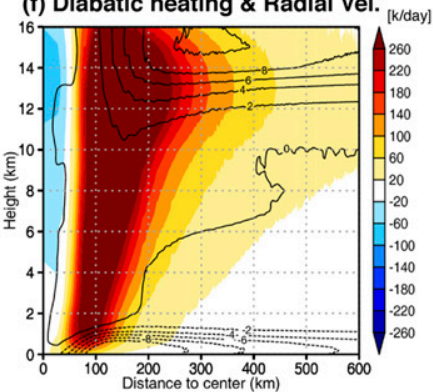

FIG. 8. As in Fig. 7, but for WNP TCs.

less than that in the WNP, indicating that the basin averaged TC activity over the ENP and NAT may be more strongly influenced by the number of TCs, while the duration of TCs may be less important. The time series of the NAT, WNP, and ENP TC activity from observations and the TCM simulations are shown in Fig. 11. Although numerous modeling studies have shown similar high correlations between simulated and observed NAT TC variability (Zhao et al. 2009; Murakami et al. 2012; Murakami et al. 2015; Chen and Lin 2013), to the (a) ENP TC Wind-Pressure Relationship

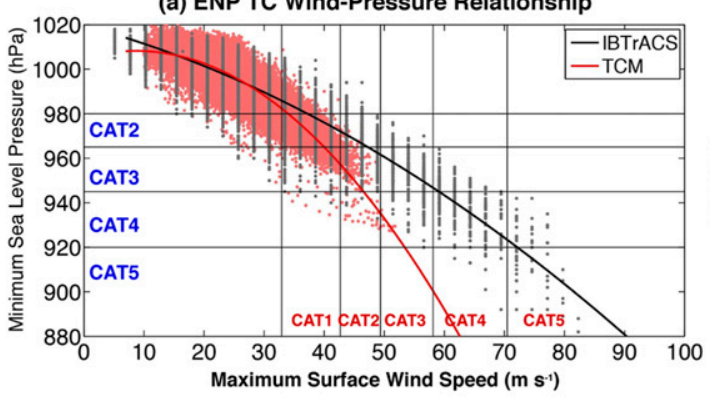

(b) ENP PDFs of TC Wind Speed $\left(\mathrm{m} \mathrm{s}^{-1}\right)$

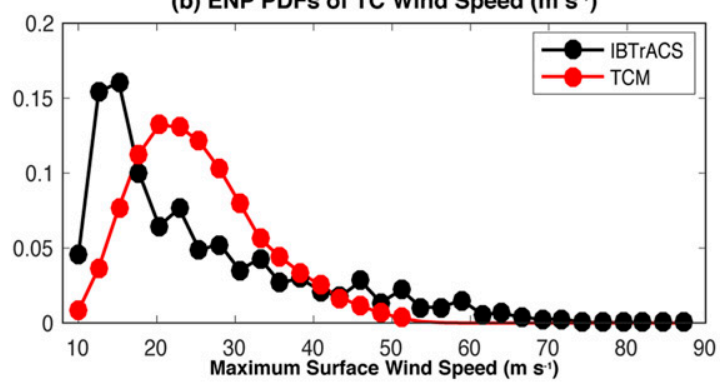

(c) GPM_HQ ENP

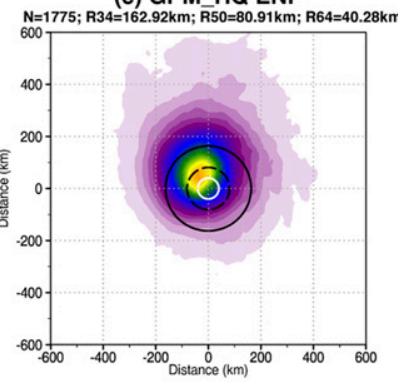

(e) TMP anomaly \& WSPD

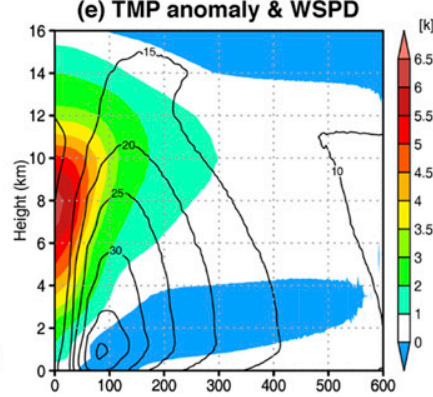

(d) TCM ENP

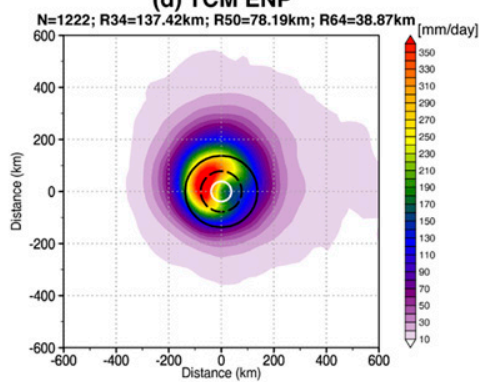

(f) Diabatic heating \& Radial Vel.

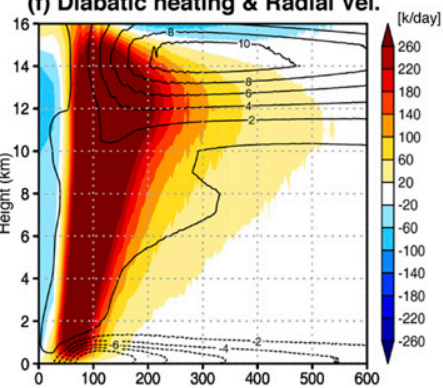

FIG. 9. As in Fig. 7, but for ENP TCs. 
(a) OLR

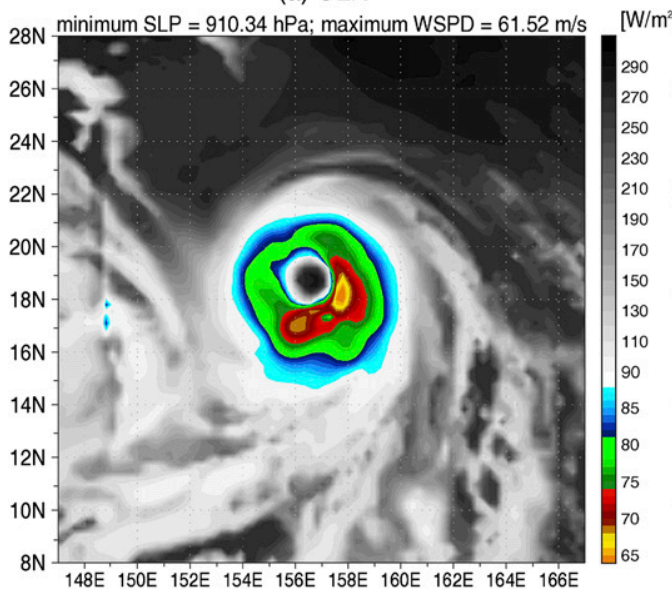

(b) Rain Rate and 10-m Wind Vector

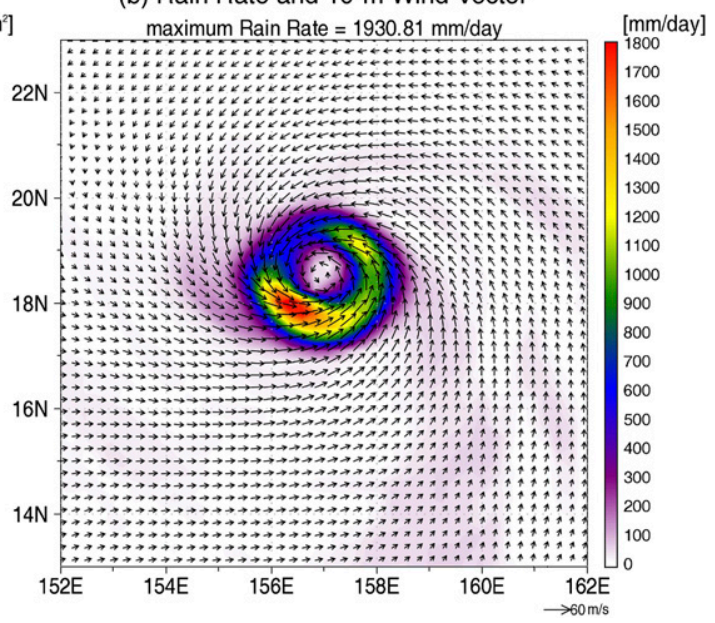

FIG. 10. A snapshot of TCM simulated sample hurricane fields of (a) outgoing longwave radiation $\left(\mathrm{W} \mathrm{m}^{-2}\right)$ and (b) precipitation rate (shading; $\mathrm{mm} \mathrm{day}^{-1}$ ) and $10-\mathrm{m}$ wind vector $\left(\mathrm{m} \mathrm{s}^{-1}\right)$.

best of our knowledge, only a very limited study (Camp et al. 2015) has demonstrated the concurrent significant correlations of WNP, ENP, and NAT TC activity in a single model configuration. Furthermore, the TCM prescribes only SST and northern and southern boundary conditions, with no nudging of the large-scale momentum or thermal fields toward the observations. These results highlight the potential feasibility of using the TCM to predict seasonal TC activity, if TC-season SSTs and lateral boundary conditions can be well predicted.

El Niño-Southern Oscillation is one of the dominant climate modes that modulate TC activity at interannual time scales (Gray 1984; Wang and Chan 2002; Camargo and Sobel 2005; Camargo et al. 2007; Fu et al. 2017). Figure 12 compares the composite anomalies of TC track density during El Niño and La Niña phases from observations and the TCM hindcast simulation. The different phases of the ENSO cycle are determined by the June-November seasonal mean value of the detrended Niño-3.4 index. The seven seasons $(20 \%$ of the cases) with the highest Niño-3.4 index values are defined as El Niño seasons $(1982,1987,1991,1997,2002,2004$, and 2015), while the seven seasons with the lowest Niño3.4 index values are defined as La Niña seasons (1988, 1998, 1999, 2000, 2007, 2010, and 2011). Since the TCM simulation consists of a 15-member ensemble with identical SSTs prescribed for each season, the ensemble average significantly reduces the influence of atmospheric internal variability on delineating ENSO's impact on TCs, giving rise to more smoothed spatial structures in the model than in the observations.

During El Niño events, both observations and the TCM present a marked west-east contrast pattern in the
WNP, with more TC genesis occurring toward the central Pacific. The location of the peak in positive genesis anomalies in the WNP is also well simulated by the model, which may imply a reasonable simulation of the eastward extension of the monsoon trough during El Niño (Wu et al. 2012).

TC activity in the NAT during El Niño is largely suppressed, which is primarily associated with an increase of the vertical wind shear and decrease of midlevel atmospheric humidity (Camargo et al. 2007).

TABLE 1. The correlation between observed and TCM simulated interannual TC variability over different ocean basins. TS, HU, and ACE indicate the number of named tropical cyclones and hurricanes and the accumulated cyclone energy. The ensemble mean is based on a 15-member ensemble, while the maximum and minimum correlation coefficients are obtained among the distinct combination sets from total of 15 -member ensemble. Two asterisks $(* *)$ and one asterisk $(*)$ denote statistical confidence at the $99 \%$ and $95 \%$ level, respectively.

\begin{tabular}{lccc}
\hline \hline & $\begin{array}{c}\text { Ensemble } \\
\text { mean }\end{array}$ & $\begin{array}{c}\text { Combination } \\
\max \end{array}$ & $\begin{array}{c}\text { Combination } \\
\min \end{array}$ \\
\hline NAT TC & $0.63^{* *}$ & $0.75^{* *}$ & $0.32^{*}$ \\
NAT HU & $0.62^{* *}$ & $0.70^{* *}$ & $0.33^{*}$ \\
NAT ACE & $0.61^{* *}$ & $0.71^{* *}$ & $0.33^{*}$ \\
WNP TC & $0.48^{* *}$ & $0.58^{* *}$ & 0.16 \\
WNP HU & $0.64^{* *}$ & $0.72^{* *}$ & $0.33^{*}$ \\
WNP ACE & $0.80^{* *}$ & $0.86^{* *}$ & $0.51^{* *}$ \\
ENP TC & $0.65^{* *}$ & $0.75^{* *}$ & 0.30 \\
ENP HU & $0.60^{* *}$ & $0.77^{* *}$ & 0.06 \\
ENP ACE & $0.64^{* *}$ & $0.72^{* *}$ & $0.32^{*}$ \\
NIO TC & 0.13 & $0.38^{*}$ & 0.01 \\
NIO HU & -0.23 & $-0.47^{* *}$ & -0.05 \\
NIO ACE & -0.16 & $-0.47^{* *}$ & -0.01 \\
\hline
\end{tabular}



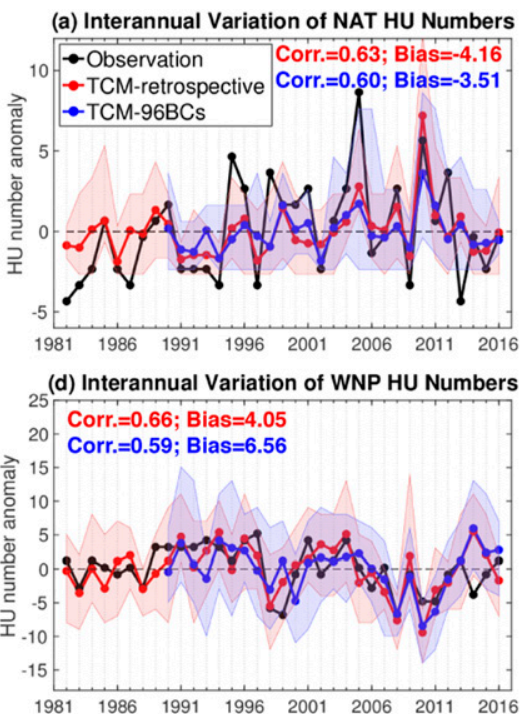

(g) Interannual Variation of ENP HU Numbers

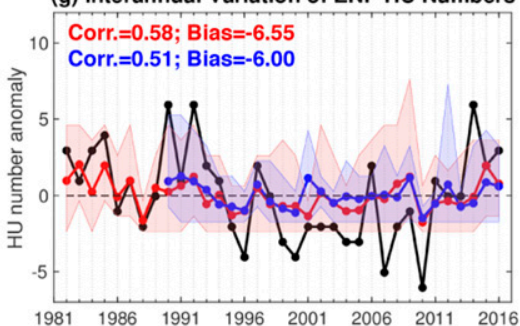

(b) Interannual Variation of NAT TC numbers

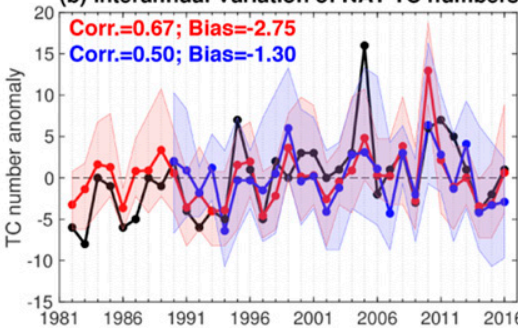

(e) Interannual Variation of WNP TC numbers

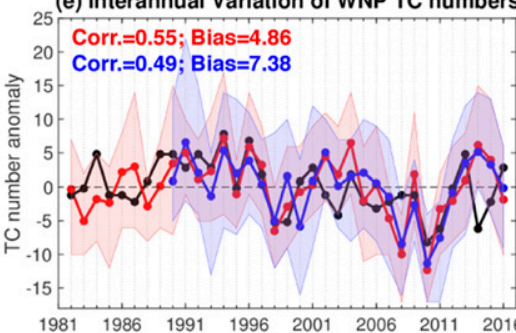

(h) Interannual Variation of ENP TC numbers

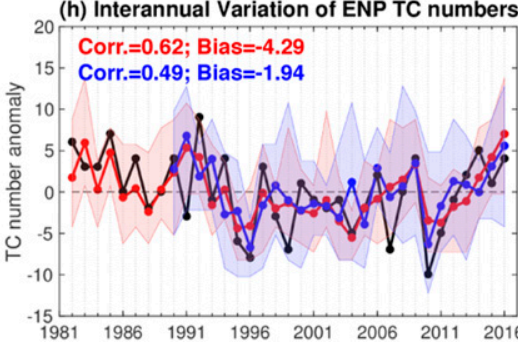

(c) Interannual Variation of NAT ACE

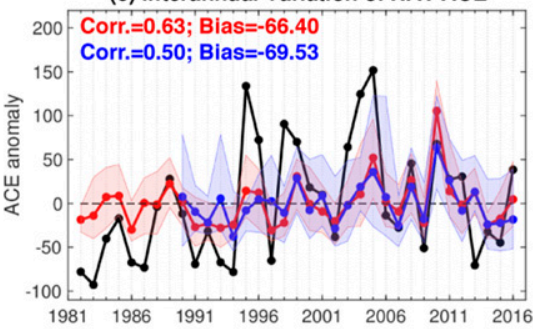

(f) Interannual Variation of WNP ACE

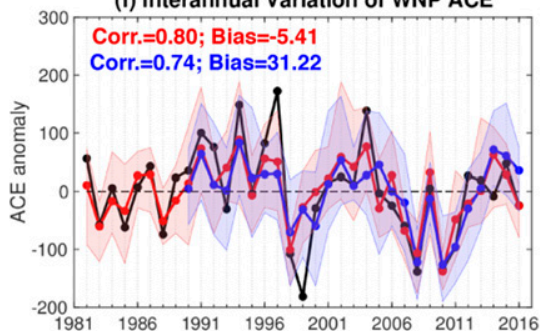

(i) Interannual Variation of ENP ACE

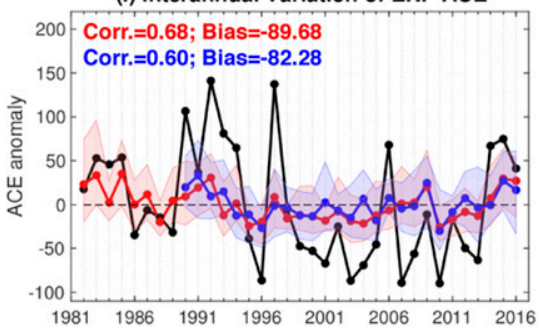

FIG. 11. Time series of NAT (a) number of hurricanes, (b) number of all TCs, and (c) ACE from 1 Jun to 30 Nov from observations (black curves), the ensemble averaged TCM hindcast simulation (red curves), and the ensemble averaged TCM fixed boundary simulation (blue curves; see details in the main text). Each time series is normalized by subtracting the corresponding climatology. The correlation and bias values listed in each panel are calculated during the period of 1990-2016 (see details in the main text). Shadings indicate the range of the minimum and maximum along the simulation ensemble members. (d)-(f) As in (a)-(c), but for results in the WNP. (g)-(i) As in (a)-(c), but for results in the ENP

Analogous to the WNP, the ENP TC activity also shows intrabasin variations, with more active TC activity shifted to the open ocean, but relatively dormant activity over the eastern nearshore area. This intrabasin variation has been linked with Central American gap wind variability ( $\mathrm{Fu}$ et al. 2017). Although the simulated suppression of TC activity in the eastern portion of the ENP extends farther west relative to the observations, the TCM overall reproduces very faithfully the TC activity anomalies during El Niño years. (a) Observation: El Niño - Climatology

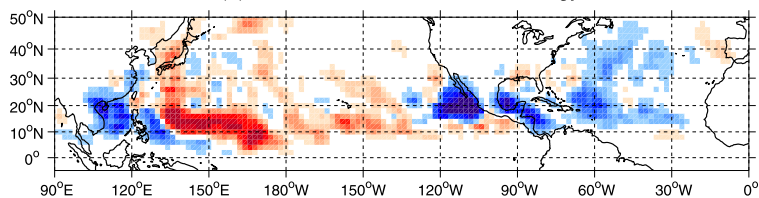

(c) TCM: EI Niño - Climatology

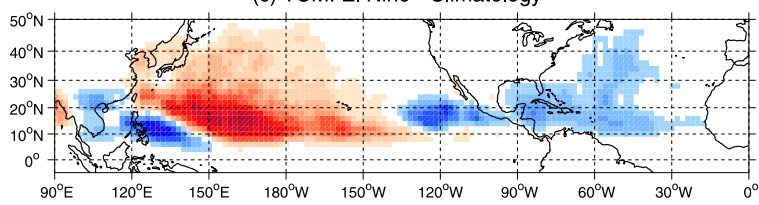

(b) Observation: La Niña - Climatolog

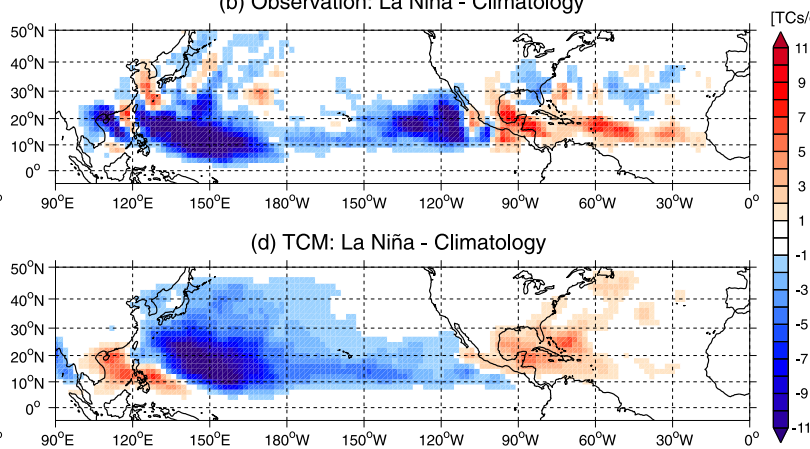

FIG. 12. Observed composites of TC track density anomaly (number of TC records per decade) for (a) El Niño and (b) La Niña years. (c),(d) As in (a),(b), but anomalies are calculated from the TCM hindcast simulation ensemble mean. 
In contrast to the El Niño years, the observed westeast variation of WNP TC activity during La Niña years is less remarkable, and the TC activity is overall decreased in the whole WNP basin. However, the TCM instead largely produces TC activity with the opposite sign of changes than during El Niño, with positive anomalies in the South China Sea and the Philippine Sea and negative anomalies in the remainder of the basin. In the ENP, both observations and the model show consistently weaker than normal TC activity, whereas the TCM underestimates the negative anomaly. Unlike El Niño, the spatially dependent TC responses within the ENP are substantially weakened during La Niña events, suggesting that La Niña's influence on ENP TC activity is not simply inverse to that during El Niño, and local topography may have asymmetric impacts on TC activity along the coastal area.

\section{b. Intraseasonal variability}

At intraseasonal time scales (30-90 days), the Madden-Julian oscillation (MJO) is the dominant mode of variability in the tropics, and can significantly modulate global TC activity. Generally, the probability of TC genesis is typically larger during or just after the strong MJO convective phase local to the TC basin (Maloney and Hartmann 2000a,b; Camargo et al. 2009; Klotzbach 2014; Lee et al. 2018). These observational studies suggested that the MJO may play a key role in intraseasonal predictability of TCs. Thus, to make skillful TC predictions at subseasonal time scales, it is important to evaluate whether models can faithfully reproduce the MJO and its linkage with TC genesis in their hindcast mode.

Figure 13 shows Wheeler-Kiladis diagrams (Wheeler and Kiladis 1999) of zonal wavenumber-frequency cross spectra of OLR and 850-hPa zonal wind from observations and the TCM hindcast. The meridionally symmetric and asymmetric components are presented in the top and bottom panels, respectively. Within the MJO regime (30-90-day time period and zonal wavenumber 1-3), the TCM shows slightly weaker but comparable spectral peaks to observations. Besides the MJO, other tropical waves such as Kelvin waves, equatorial Rossby (ER) waves, asymmetric eastward inertial gravity (EIG) waves, and mixed Rossby-gravity waves are also reasonably captured. These results again highlight the TCM's value and capability in studying dynamical processes in tropical regions.

By categorizing the MJO into eight difference phases, following the approach of Wheeler and Hendon (2004), Fig. 14 compares composites of OLR and corresponding TC genesis density anomalies between the observations and the TCM hindcast. Using multivariate empirical orthogonal functions (MEOFs) to decompose the normalized daily mean OLR and zonal wind at 200 and $850 \mathrm{hPa}$ from the observations, an observed MJO index is obtained based on the first two leading principal components ( $\mathrm{PC} 1$ and $\mathrm{PC} 2$ ). A model-based index is then obtained by projecting TCM simulated fields onto the same EOF patterns. The TCM composites of negative OLR anomalies based on the model MJO index demonstrate eastward propagation patterns that are remarkably consistent with observations. Although the composite magnitude is relatively weaker in the simulation, which may be partially due to the ensemble averaging, the fractions of each MJO phase are similar, indicating that the simulated MJO is not simply locked to specific phases. In addition, consistent with observations and various previous studies, TC genesis is also generally more frequent during the active MJO phases for each basin in the TCM. These modulations are even more robust in the NIO, WNP, and ENP in terms of changing in amplitudes, while the MJO's impacts on NAT TCs are primarily confined to the GoM region, supporting previous observational analyses (e.g., Maloney and Hartmann 2000b).

The above results demonstrate that the TCM is skillful in reproducing both the MJO and its modulation of TC activity. At the same time, the TCM is also capable of simulating realistic spatial patterns of TC activity and TC structures. These results, in combination with a realistic representation of the power spectra of tropical waves, make the TCM a very useful tool to study the interactions between tropical cyclogenesis and various equatorial waves.

\section{Experimental seasonal forecasts of the 2017 and 2018 hurricane seasons}

Given the skillful TCM hindcasts of intraseasonal-tointerannual TC variability in various tropical basins, we conducted a set of experimental TC seasonal forecasts for the 2017 and 2018 hurricane seasons to provide a preliminary assessment of the TCM's ability to predict TC activity before the hurricane seasons. Each forecast ensemble consists of 30 members, initialized on 0000 and 1200 UTC, 1 May to 15 May, and all end on 1 December with the same lateral boundary conditions and SSTs. Forecast initialization in May approximately corresponds to the timing of many currently operational extended range seasonal TC forecasts, including that of Colorado State University (https://tropical.colostate.edu/archive-ofpast-forecasts/).

To create the SST forcing for the TCM seasonal TC forecasts, we used bias-corrected 30-member ensemble averaged 6-hourly SST from operational CFSv2 seasonal forecasts. The bias correction procedures strictly 
(a) Observation
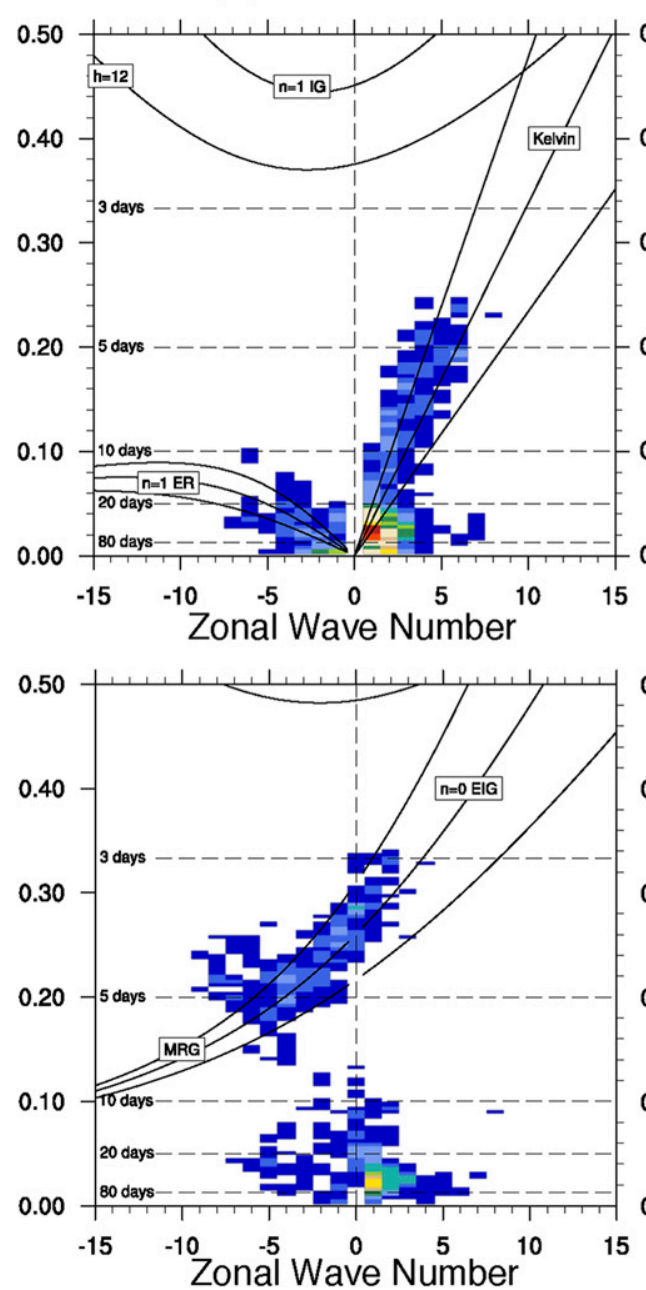

(b) TCM
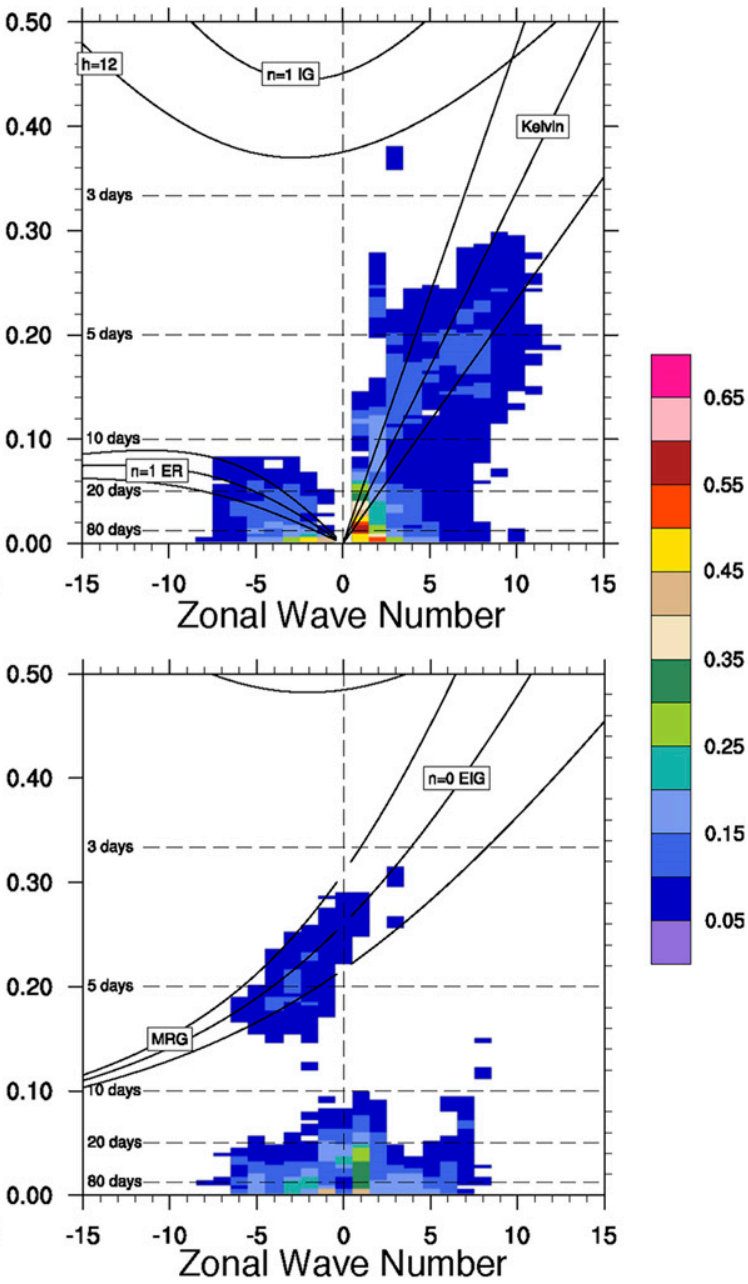

FIG. 13. Wheeler-Kiladis diagram of the coherence squared between meridionally (top) symmetric and (bottom) asymmetric components OLR and 850-hPa zonal wind from (a) 1982-2016 observation and (b) the 15-member ensemble TCM retrospective simulation. ER, IG, MRG, and EIG are equatorial Rossby wave, inertia-gravity wave, mixed Rossby-gravity wave, and eastward inertia-gravity wave, respectively.

followed the guideline provided by the NCEP CFSv2 SST forecast (https://www.cpc.ncep.noaa.gov/products/ people/wwang/cfsv2fcst/CFSv2SST8210.html).

Using the TCM imposes the additional challenge of obtaining a data source for the northern and southern lateral boundary conditions. We chose not to use the CFSv2 seasonal prediction data in order to avoid prescribing potential forecast model biases. Instead, the lateral boundary conditions were derived from CFSR in the 1996 hurricane season, which was characterized by a neutral phase of the Atlantic multidecadal oscillation (AMO), ENSO, and AMM, so that the vicinity of the southern and northern edges are not affected by strong phases of climate modes. With such configurations, we assume the northern and southern boundary conditions in the seasonal forecast simulations are prescribed to a "climatology-like" condition, and the seasonal TC predictability is primarily contributed by the SSTs. We hypothesize that this approach is reasonable in the majority of hurricane seasons, but recognize that the assumption may fail during the rare seasons when extratropical influences are important for determining TC activity (Zhang et al. 2016, 2017; Mapes et al. 2008), such as during 2013 (which represented a seasonal forecast bust for many centers).

To examine this critical assumption, we made another suite of experiments in which the model is forced with interannually varying historical SSTs, but a perpetual lateral boundary condition of the 1996 season (hereafter TCM-96LBC). The TCM-96LBC consists of 10 ensemble members for the 1990 to 2016 seasons. Blue curves in 
(a) Observation OLRa

(b) Observation GDa

(c) TCM OLRa

(d) TCM GDa

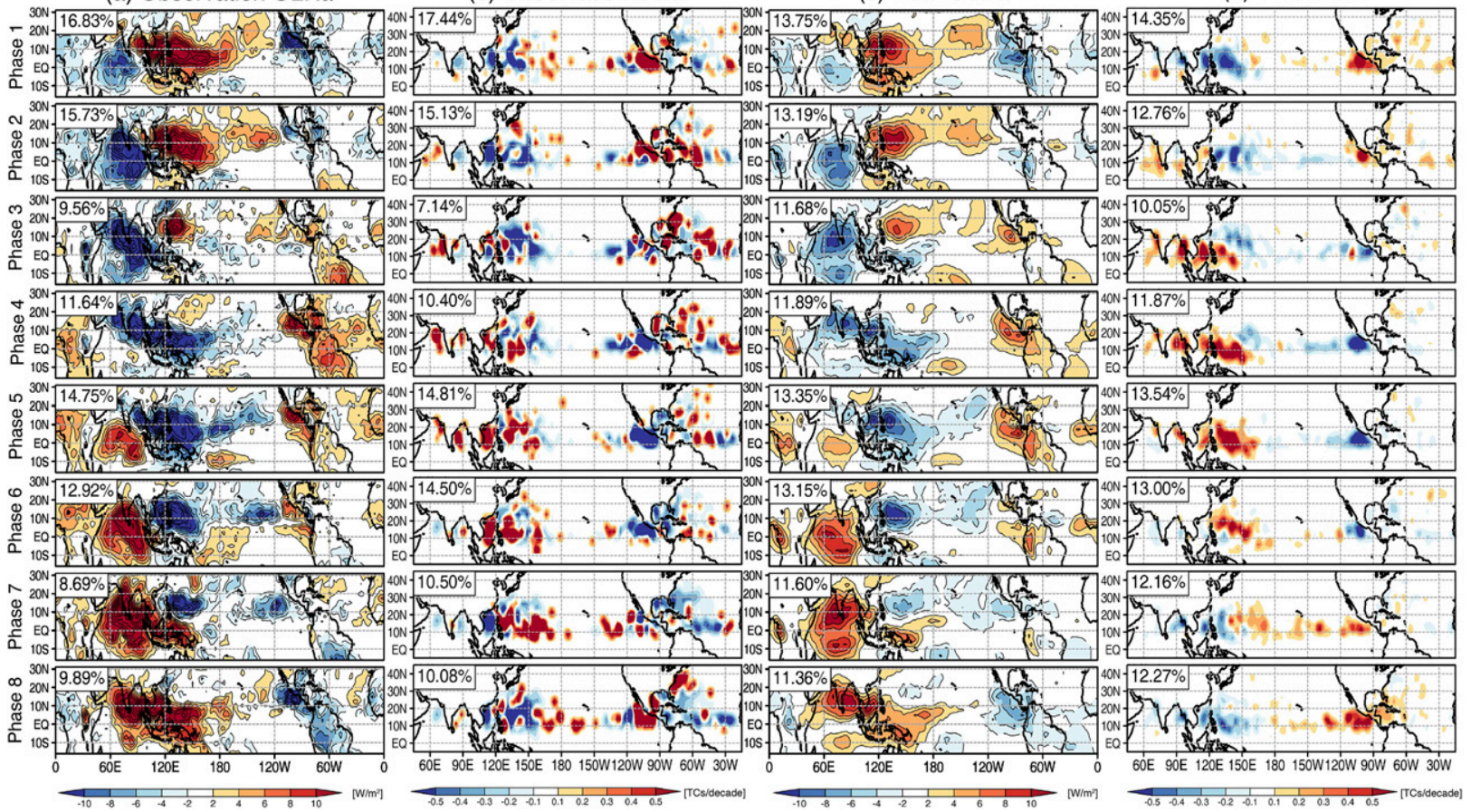

FIG. 14. Observed composites of (a) OLR anomaly $\left(\mathrm{W} \mathrm{m}^{-2}\right.$ ) and (b) TC genesis density anomaly (number of TC records per decade) for each MJO phase during 1982-2016. (c),(d) As in (a),(b), but for TCM retrospective simulation results. The fractions of each MJO phase are listed in the bottom of each panel.

Fig. 11 show the time series of TC activity from the TCM-96LBC simulation, while the blue shadings indicate the minimum and maximum values among the ensemble members. The correlation and bias values are calculated from the ensemble mean of TCM hindcast (red) and TCM-96LBC (blue) simulations, relative to the 1990-2016 observations. Compared to the hindcast simulation, the correlations in TCM-96LBC are somewhat decreased but still significant at the $99 \%$ confidence level in all three major TC basins. Moreover, the TCM-96LBC simulation exhibits stronger TC activity than that in hindcast simulation, and the ensemble spreads are larger even though the actual ensemble size is smaller. The results suggest that although the model northern and southern boundaries are far from the tropics, they still contribute to simulated TC variability from the long-term climate perspective. However, in terms of interannual TC variability, SST is apparently the dominant driver, while the northern and southern atmospheric boundary constraints in the extratropics (i.e., Rossby wave breaking, potential vorticity streamers) can also affect the mean state of TC activity to some extent. A detailed analysis of the impact of the northern and southern boundary constraints on the TC climatology is beyond the scope of this work and will be pursued in the future. In the following discussion, all of the TCM predicted metrics are subtracted by the 1990-2016 climatology from the TCM-96LBC simulation. By doing so, we assume the influences from lateral boundary conditions on the seasonal TC predictions are offset.

Figure 15 shows the bias-corrected SST anomalies during the 2017 and 2018 hurricane seasons from the operational CFSv2 seasonal forecasts and the 2017 season observation. These SST anomalies are with respect to 1982-2010 climatology. With the early May initial conditions, CFSv2 predicted the developing La Niña-like cooler than normal SST conditions in the Pacific and anomalous warmer Atlantic SSTs, associated with a positive phase of AMM, during the 2017 hurricane season, which were generally in agreement with the observations. For the 2018 hurricane season, the CFSv2 forecasts initialized in the early May predicted a moderate La Niña and near normal NAT SSTs. In contrast, the observations suggest the combination of a central Pacific type of El Niño (Kug et al. 2009; or known as El Niño Modoki; Ashok et al. 2007) and the Pacific meridional mode (PMM; Chiang and Vimont 2004; Chang et al. 2007) during the 2018 season, and an anomalous cooling pattern in the eastern NAT. These inconsistencies between observed and predicted SSTs may contribute to biases in the 2018 seasonal TC predictions. 
(a) Predicted 2017 JJASON SSTa

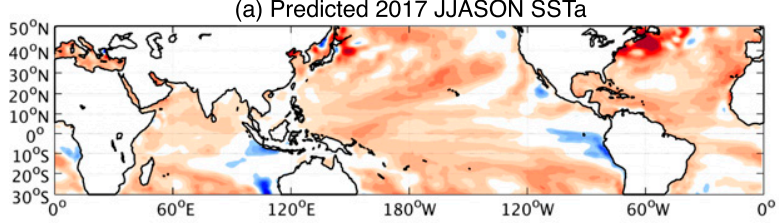

(c) Predicted 2018 JJASON SSTa

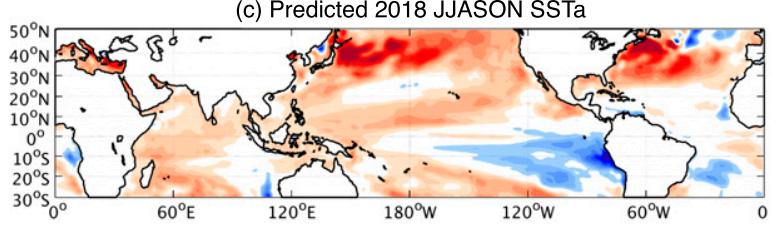

(b) Observed 2017 JJASON SSTa

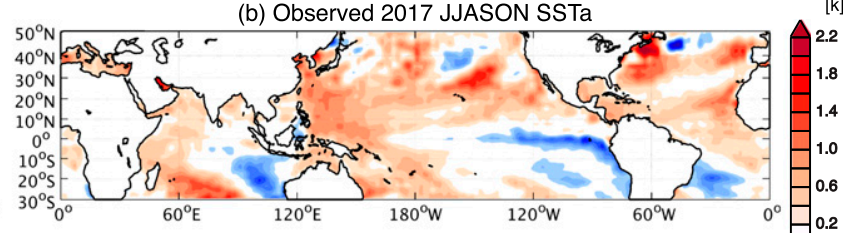

(d) Observed 2018 JJASON SSTa

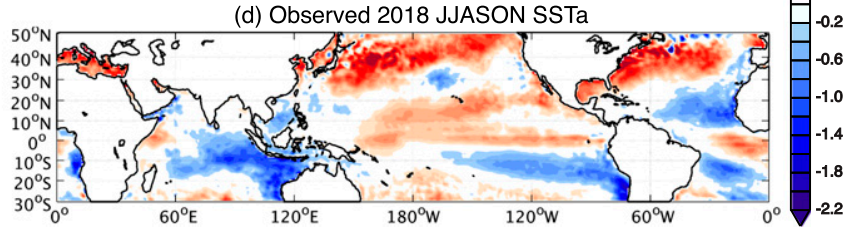

FIG. 15. (a) CFSv2 seasonal predicted 2017 June-November seasonal mean SST anomaly (K). SST anomaly is the result from the 30member ensemble average, with CFSv2 seasonal forecast initial conditions set at 0000 and 1200 UTC, 1 to 15 May. Predicted SSTs are first bias-corrected based on 1990-2010 CFSv2 hindcasts, and anomalies are then further calculated as the departure from CFSR 1982-2010 climatology. (b) Observed 2017 June-November seasonal mean SST anomaly, with respect to 1982-2010 climatology. (c),(d) As in (a),(b), but for the 2018 season.

Figure 16 shows boxplots for predicted TC activity superposed on the observations (stars). Note that the official summaries of the 2018 hurricane seasons were not publicly available at this writing, and the observation for the 2018 season is obtained from the Colorado State University real-time archive (http://tropical.atmos. colostate.edu/Realtime/). To account for model bias, the predicted TC activity is rescaled based on the TCM96LBC experiment and 1990-2016 observations. For the 2017 season, the TCM predicts the high risk of a hyperactive NAT hurricane season, with 15-21 named TCs, 7-13 hurricanes, and ACE index of 145-190, in terms of the 25 th and 75 th percentile values of the 30 -member ensemble forecasts. All of these predicted ranges, even with lower bounds, are above the long-term climatology of 1990-2016. In reality, 16 named tropical storms and 10 hurricanes occurred in NAT during June-November 2017, with an ACE index of 225. In the WNP and ENP, the results of the 2017 ensemble TC forecasts oscillate around the 1990-2016 climatology, indicating a near-normal condition, which are also consistent with the observation.

In addition to the skillful basin-integrated predictions of TC activity, the TCM also seems to be capable of forecasting certain aspects of the TC spatial distribution prior to the beginning of the official hurricane season. Figure 17 illustrates the TC track density anomaly from the ensemble mean seasonal predictions and observations. The higher than normal frequency of TC attacks in GoM and the east of Caribbean Sea is captured by the TCM. In the central Pacific (date line to $140^{\circ} \mathrm{W}$; partial of ENP), no TC genesis was observed for the first time since 2012 (Roberts and Pasch 2018), which is also reasonably forecasted by the TCM that predicts a large negative anomaly pattern. Although the predicted WNP TCs have higher chances of generating closer to the continent, which is generally consistent with the observation due to the predicted La Niña condition, we also find the large discrepancies in the southeast quadrant of WNP. Given the fact that TCM is able to present faithful observed ENSO's modulations on TC distributions (Fig. 12), we speculate that this disagreement may arise from the underestimation of the amplitude of La Niña condition (Fig. 15a) in the CFSv2 seasonal prediction.

Next we consider the 2018 TC predictions. Given that the predicted NAT SSTs during the 2018 hurricane season were much cooler than in 2017, the Atlantic SST anomalies tend to offset the influences on NAT TC activity from the growing La Niña predicted by the CFSv2 (Patricola et al. 2014). In other words, the forecasted Pacific and Atlantic SST anomalies counteract in terms of their influence on forecasted NAT TC activity. As a result, the TCM predicts a near-normal seasonal outlook with 9-14 named TCs, 5-9 hurricanes, and an ACE index of 90-150 for the 2018 hurricane season. In contrast, the TCM suggests an increased probability of above normal WNP TC activity during 2018 hurricane season, with 18-25 named TCs, 13-17 hurricanes, and an ACE index of 265-325. For the ENP, although it has a higher possibility of abundant named TCs, the hurricane number and ACE are more likely analogous to the climatology, probably due to cooler SSTs in the ENP that inhibit TC intensification. The predicted TC track density also suggest basinwide stronger (weaker) TC activity in the WNP (NAT), while the ENP still shows the east-west contrast pattern, with decreased activity in the central Pacific but increased in the eastern portion.

Since the official release of best track data for the 2018 hurricane season is not yet publicly available, we assess our predictions with the Colorado State University realtime TC activity data archive. The TCM's TC prediction 

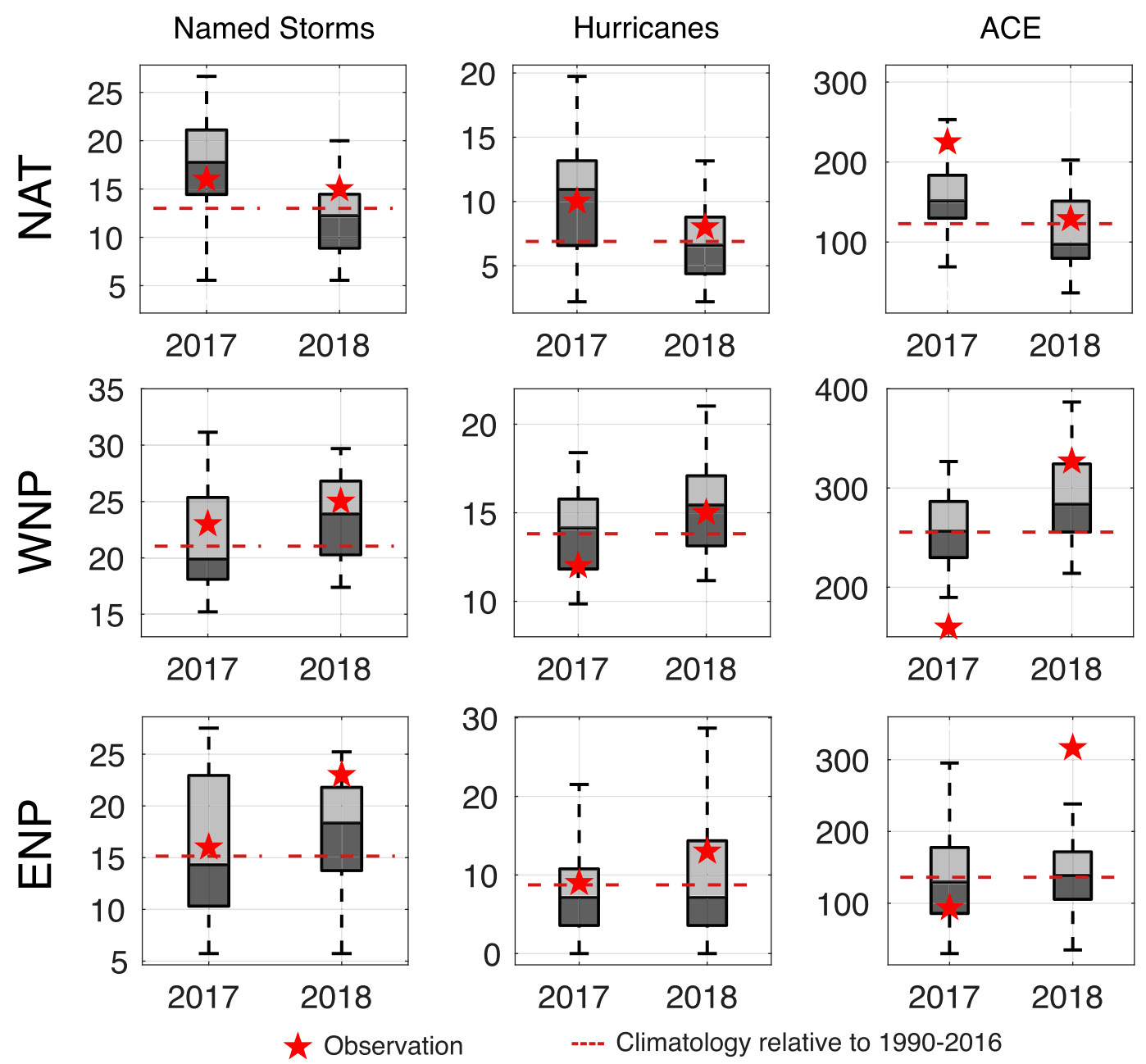

FIG. 16. Boxplots of TCM seasonal forecasts for named storm counts, hurricane counts, and ACE $\left(10^{4} \mathrm{kt}^{2}\right)$ over the North Atlantic (NAT), western North Pacific (WNP), and eastern North Pacific (ENP). Each panel shows plots for 2017 and 2018 seasons using rescaled results from 30-member ensemble simulation. The red stars indicate the observed value during each season, and dashed maroon lines denote 1990-2016 climatology. The boxes represent the first quartile, median, and third quartile values, while the dashed vertical lines show the lowest and highest values within the 1.5 interquartile ranges. Note that observations for 2017 season are from TC best track data, whereas data for 2018 season are from the Colorado State University (CSU) real-time data archive, as best track data for 2018 hurricane season were not available at the time when the manuscript submitted.

appears to be in line with the observations in the NAT and WNP, but the predicted TC activity in the ENP is underestimated. Specifically, the predicted ENP ACE index is near normal, while in reality it was recordbreaking. This is possibly caused by flaws in the ENSO prediction, as the observed warmer SSTs would have been more favorable for the TC intensification.

\section{Summary and discussion}

We have tailored the WRF tropical channel model to better simulate the characteristics and climatology of TCs, as well as their subseasonal-to-interannual variability over the Northern Hemisphere. We have also developed and tested a TCM-based framework for seasonal TC prediction. Based on the early work by Patricola et al. (2016, 2017, 2018), the TCM used in this study covers the global tropics and parts of midlatitudes from $30^{\circ} \mathrm{S}$ to $50^{\circ} \mathrm{N}$ with a TC-permitting $27-\mathrm{km}$ horizontal resolution. The improvements made in this study focus on carefully reconfiguring and retuning model physics in order to achieve more a realistic large-scale mean state and TC climatology. We conducted a large ensemble of retrospective hindcast simulations from 1982 to 2016 to investigate the model performance in simulating intraseasonal-to-interannual TC variations. 
(a) TCM seasonal prediction of 2017 hurricane season

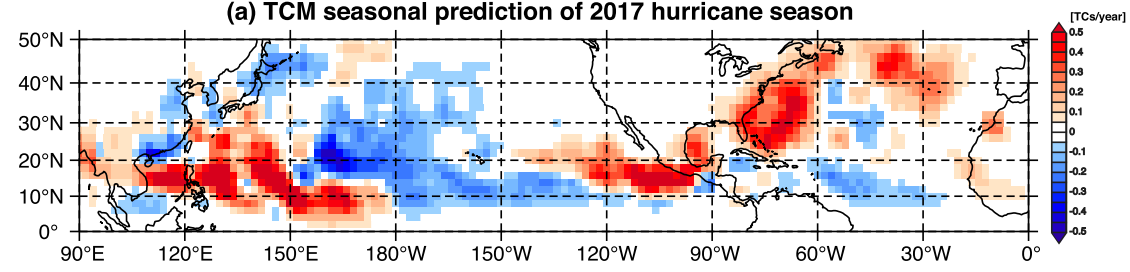

(b) Observation of 2017 hurricane season

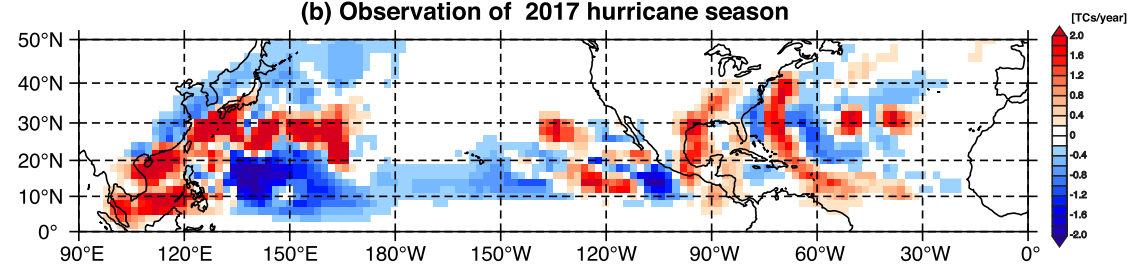

(c) TCM seasonal prediction of 2018 hurricane season

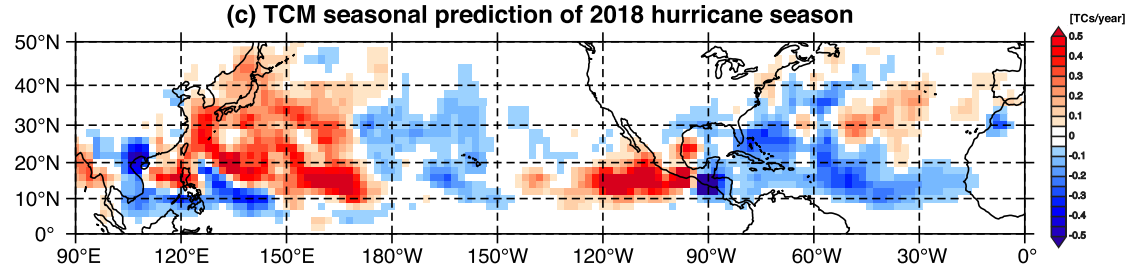

(d) Observation of 2018 hurricane season

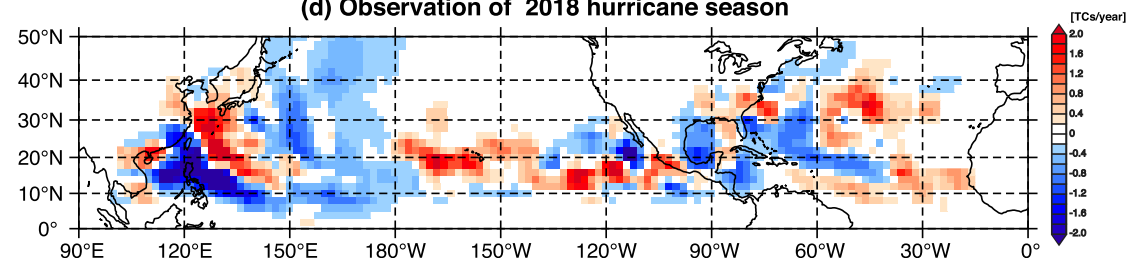

FIG. 17. 2017 hurricane season TC track density anomaly (number of TC records per year) from (a) 30-member ensemble averaged TCM seasonal prediction and (b) best track data. Anomaly is relative to 1990-2016 climatology. (c) As in (a), but for TCM seasonal prediction of 2018 hurricane season. (d) As in (b), but for observations of 2018 hurricane season. Note that observations for 2017 season are from TC best track data, whereas data for 2018 season are from Colorado State University (CSU) real-time data archive, as best track data for 2018 hurricane season were not available at the time when the manuscript was submitted.

In addition, we also examined the impact of lateral boundary conditions on seasonal TC predictions, performing and evaluating an ensemble of experimental seasonal predictions for 2017 and 2018 using the TCM forced with the predicted SST anomalies derived from the CFSv2 operational forecasts.

The improved TCM not only shows substantially reduced biases in simulating the mean climate state in the tropics, but also captures the environmental factors tightly linked with TC activity remarkably well. It reproduces a realistic climatological spatial distribution of TCs in all four TC basins of the Northern Hemisphere (the NIO, WNP, ENP, and NAT). More importantly, the simulated structures of intense TCs are quite consistent with the observed, in terms of both TC-related wind and precipitation fields. The results indicate that, although the $27-\mathrm{km}$ TCM lacks the ability to simulate strong TCs partly because of deficient horizontal resolution, it is a well-suited tool for studying the response of TCs to climate variability and anthropogenic climate change, and can be valuable for assessing the social and economic influences of TCs.

In addition, the TCM exhibits substantial skill in capturing subseasonal-to-interannual variability of TC activity. The correlations between observed and simulated interannual TC activity are significantly robust in the WNP, ENP, and NAT, but show little skill in the NIO. In particular, the ACE index achieves a high correlation of 0.80 in the WNP during the $35-\mathrm{yr}$ period. Although a number of previous studies have demonstrated similar high correlations of TC activity in various individual TC basins using global climate models (Zhao et al. 2009; Murakami et al. 2011; Chen and Lin 2013), this study represents one of the very few climate models to successfully capture significant correlations in all three 
TC basins (i.e., the WNP, ENP, and NAT) concurrently in a single model configuration after Camp et al. (2015). At the intraseasonal time scale, the TCM produces a realistic Madden-Julian oscillation (MJO), whose active convection phase enhances TC genesis over the globe. It indicates the TCM's potential skill in predicting TC genesis at subseasonal time scales, as evaluated using a largeensemble simulation that enables greater sample sizes of MJO events than in observations. We believe a further analysis of this large number of MJO events will help improve our understanding of intraseasonal dynamics of the tropical atmosphere, leading to the understanding of MJO predictability and its potential linkage to the largescale environment as well as TC activity.

We also examined the performance of the TCM in a set of experimental seasonal TC predictions for 2017 and 2018 forced with perpetual lateral boundary conditions but predicted SSTs initialized in May. We found that the predictability of seasonal TC activity is primarily driven by SSTs, while high-frequency midlatitude atmospheric variability may contribute to the climatology of TC activity. Initial tests for seasonal forecasts of the 2017 season reveal that the TCM can have substantial skills in predicting the seasonal outlook of TC activity provided that predicted SSTs are sufficiently accurate. For the 2018 season, the TCM underestimates ENP TC activity possibly due to an incorrect prediction of SSTs in the equatorial eastern Pacific. Given that the skillful ENSO prediction by dynamical atmosphere-ocean coupled models initialized in early boreal summer still remains an unmet challenge (Kumar et al. 2017), the current strategy that relies on the predicted SSTs from various models may limit the upper bound of TCM seasonal TC prediction skill for forecasts initialized before the start of the hurricane season. We are now developing a seasonal prediction system that couples the atmospheric TCM with an ocean component derived from either the Regional Ocean Modeling System (ROMS) or a slab ocean model (SOM). More comprehensive studies of seasonal TC forecasting using the coupled TCM are planned in the near future.

In summary, the tailored TCM is a well-suited tool for studying the climatology and variability of TCs. In addition, our results suggest the TCM may provide skillful seasonal predictions of TC activity and spatial anomalies. Compared to conventional high-resolution general circulation models, the TCM is computationally cheaper (e.g., a 7-month simulation can be completed in 9 wallclock hours, with 768 CPUs on the Stampede2 supercomputer at TACC). This computational efficiency is essential to generate large ensemble of simulations. More importantly, due to the extensive range of flexibility in the WRF system (model resolutions, physical parameterizations, data assimilation systems, etc.), we believe the TCM can offer a valuable and powerful alternative to global climate models for TC simulation and prediction studies.

Acknowledgments. This research is supported by U.S. National Science Foundation Grant AGS-1462127, the Natural Science Foundation of China (41490644 and U1406401), and China's National Basic Research Priorities Programmer (2013CB956204 and 2014CB745000). The Texas Advanced Computer Center (TACC) at The University of Texas at Austin and the Texas A\&M Supercomputing Facility provided high-performance computing resources that contributed to the research results reported in this paper. D.F. acknowledges support from the China Scholarship Council. C.M.P. acknowledges support from the U.S. Department of Energy, Office of Science, Office of Biological and Environmental Research, Climate and Environmental Sciences Division, Regional \& Global Climate Modeling Program, under Award Number DE-AC0205CH11231. This is a collaborative project between the Ocean University of China (OUC), Texas A\&M University (TAMU), and the National Center for Atmospheric Research (NCAR) and completed through the International Laboratory for High Resolution Earth System Prediction (iHESP), a collaboration by the Qingdao National Laboratory for Marine Science and Technology Development Center, Texas A\&M University, and the National Center for Atmospheric Research.

\section{APPENDIX A}

\section{Sensitivity Experiments of Model Physics Parameterization}

Earlier TCM configurations (Patricola et al. 2016, 2017, 2018) exhibit the biggest bias over the ENP, where the westward propagation of TCs was not realistically simulated. This discrepancy in TC distribution may be primarily attributed to the bias in the simulation of strong convective systems over the ITCZ, as excessive precipitation is apparent near the Pacific coastal area of Central America [see supplemental Fig. 10 in Patricola et al. (2016)]. Thus, to minimize the model biases from the earlier TCM, we primarily focused on improving the ENP regional climate simulation.

Many previous studies have documented the importance of model physics parameterizations on regional climate simulations (Hu et al. 2010; Evans et al. 2012; Nasrollahi et al. 2012; Crétat et al. 2012; Bruyère et al. 2017). Specifically, Bruyère et al. (2017) reported that regional precipitation and TCs simulations are highly sensitive to the choice of both cumulus schemes and planetary boundary layer (PBL) schemes. Also, Katragkou 
TABLE A1. 21 sets of sensitivity experiments to investigate the optimized TCM physics parameterizations.

\begin{tabular}{|c|c|c|c|c|}
\hline & Cumulus & Microphysics & Shortwave radiation & Longwave radiation \\
\hline 1 & Kain-Fritsch & Purdue-Lin & New Goddard & RRTMG \\
\hline 2 & Kain-Fritsch & Purdue-Lin & RRTMG & RRTMG \\
\hline 3 & Kain-Fritsch & Purdue-Lin & Dudhia & RRTM \\
\hline 4 & Kain-Fritsch & Purdue-Lin & New Goddard & New Goddard \\
\hline 5 & Kain-Fritsch & WSM6 & Dudhia & RRTM \\
\hline 6 & Kain-Fritsch & WDM6 & Dudhia & RRTM \\
\hline 7 & Kain-Fritsch & Eta Ferrier & Dudhia & RRTM \\
\hline 8 & Betts-Miller-Janjić & Purdue-Lin & New Goddard & RRTMG \\
\hline 9 & Betts-Miller-Janjić & Purdue-Lin & RRTMG & RRTMG \\
\hline 10 & Betts-Miller-Janjić & Purdue-Lin & Dudhia & RRTM \\
\hline 11 & Betts-Miller-Janjić & Purdue-Lin & New Goddard & New Goddard \\
\hline 12 & Betts-Miller-Janjić & WSM6 & Dudhia & RRTM \\
\hline 13 & Betts-Miller-Janjić & WDM6 & Dudhia & RRTM \\
\hline 14 & Betts-Miller-Janjić & Eta Ferrier & Dudhia & RRTM \\
\hline 15 & New simplified Arakawa-Schubert & Purdue-Lin & New Goddard & RRTMG \\
\hline 16 & New simplified Arakawa-Schubert & Purdue-Lin & RRTMG & RRTMG \\
\hline 17 & New simplified Arakawa-Schubert & Purdue-Lin & Dudhia & RRTM \\
\hline 18 & New simplified Arakawa-Schubert & Purdue-Lin & New Goddard & New Goddard \\
\hline 19 & New simplified Arakawa-Schubert & WSM6 & Dudhia & RRTM \\
\hline 20 & New simplified Arakawa-Schubert & WDM6 & Dudhia & RRTM \\
\hline 21 & New simplified Arakawa-Schubert & Eta Ferrier & Dudhia & RRTM \\
\hline
\end{tabular}

et al. (2015) found that the use of CAM longwave radiation schemes may lead to significant biases in temperature, sea level pressure, as well as the precipitation, while these biases can be improved by using the RRTMG longwave radiation scheme ( $\mathrm{Li}$ et al. 2014). Based on these findings, we carefully designed a set of 21 sensitivity experiments (Table A1), each with a different set of physical parameterization schemes, to obtain an appropriate TCM configuration. Since the Yonsei University (YSU) PBL scheme is shown to have the smallest biases compared to

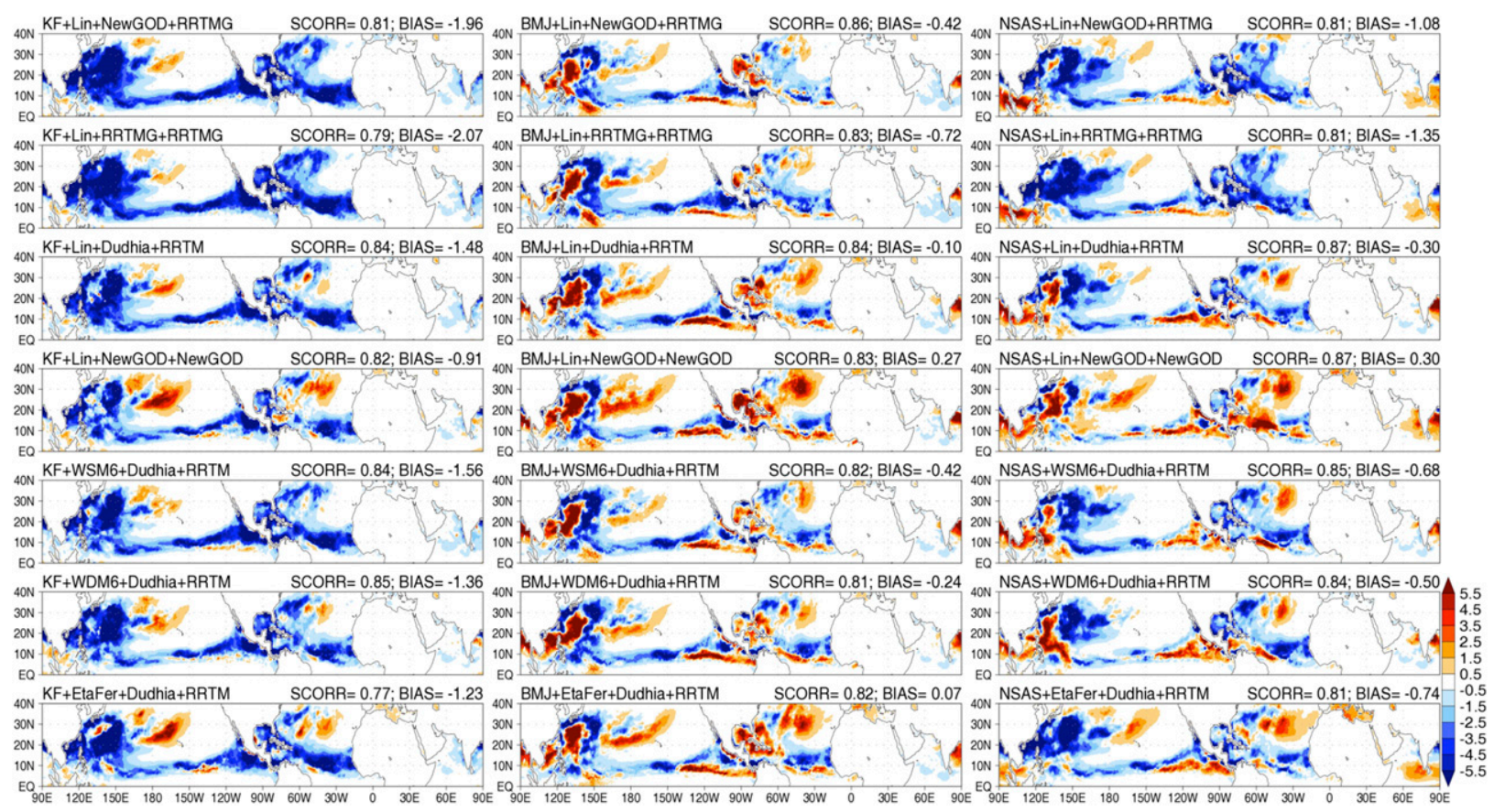

FIG. A1. Differences of GPI (unitless) that using TCM ensemble averaged sensitivity simulations with various physics parameterizations minus ERA-YOTC. The choices of model physics parameterization schemes are shown on the top left of each panel, while spatial correlation coefficients and errors are shown on the top right. 


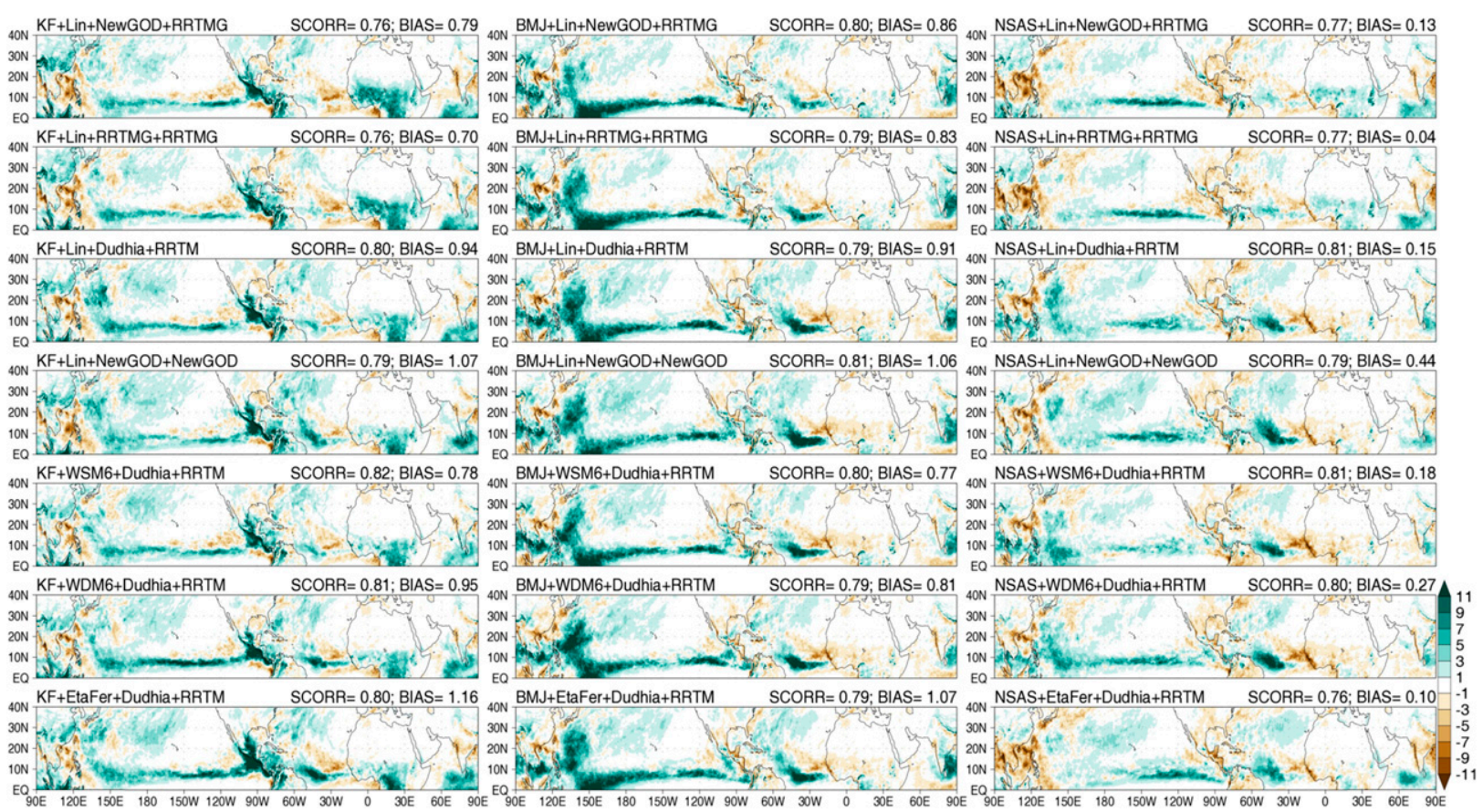

FIG. A2. As in Fig. A1, but for differences of precipitation rate $\left(\mathrm{mm} \mathrm{day}^{-1}\right)$.

surface and boundary layer observations south of the United States (Hu et al. 2010), in an area close to ENP, and can generate a moderate number of TCs (Bruyère et al. 2017), we assume that the YSU PBL scheme is also appropriate in this study.

Sensitivity simulations are initialized at 1 May 2008, with three-member ensemble for each, and outputs are archived every $6 \mathrm{~h}$ from 1 June to 1 December, after one month of spinup. The reason we chose the 2008 hurricane season to validate the TCM simulation is due to the neutral phase of ENSO and the availability of the Year of Tropical Convection (YOTC) product. YOTC is a joint research program designed to gain a better understanding of tropical convection systems, and is widely used in assessing the representation of tropical convection in atmospheric models (Waliser et al. 2012). The sensitivity experiments with various physics parameterizations were carefully evaluated in terms of the capability to represent the ITCZ and regional circulation (see Figs. A1 and A2 as examples), as well as their computational cost. We required that the selected physics parameterizations appropriately represent not only regional-scale features, such as Caribbean lowlevel jets and gap winds in Central America, but also the larger-scale regional circulation related to tropical cyclogenesis. We used the Cross-Calibrated MultiPlatform version 2 (CCMPv2) surface wind vector analyses (Atlas et al. 2011), Tropical Rainfall Measuring Mission (TRMM) multisatellite precipitation analysis, and YOTC as benchmarks, and found that the simulation with the new simplified Arakawa-Schubert (NSAS; Han and Pan 2011) cumulus scheme, PurdueLin (Lin et al. 1983) microphysics scheme, Dudhia (Dudhia 1989) shortwave radiation, and rapid radiative transfer model (RRTM; Mlawer et al. 1997) longwave radiation produced the most realistic results with moderate computational costs.

Given the limited computational resources but extensive available combinations of WRF physics parameterizations, we note that the chosen schemes may not be the best options but work appropriately in our TCM configuration.

\section{APPENDIX B}

\section{Tropical Cyclone Detection and Tracking Algorithm}

The algorithm used to detect and track TCs is adapted from Knutson et al. (2007). Using 6-hourly instantaneous TCM output, grid points in space and time satisfying the following conditions are marked as potential TC snapshots:

1) The local maximum relative vorticity at $850 \mathrm{hPa}$ exceeds $1.6 \times 10^{-4} \mathrm{~s}^{-1}$, and maximum $10-\mathrm{m}$ wind speed (WSPD) is greater than $10 \mathrm{~m} \mathrm{~s}^{-1}$. We note that $10-\mathrm{m}$ wind is diagnosed in WRF based on Monin-Obukhov similarity theory to extrapolate the wind from the lowest model level of around $30 \mathrm{~m}$ over the ocean. 
2) The local minimum of sea level pressure (SLP) that is within a distance of $2^{\circ}$ latitude or longitude from the vorticity maximum center is defined as TC center. SLP must increase by at least $4 \mathrm{hPa}$ from the TC center within a radius of $5^{\circ}$.

3) The local maximum of air temperature averaged at 300 and $500 \mathrm{hPa}$ is defined as the warm-core center. The warm-core center must also be located within a distance of $2^{\circ}$ from the TC center, and be $0.8 \mathrm{~K}$ warmer than the surrounding $5^{\circ}$ radius representing the environmental mean.

After identifying potential TC snapshots based on the thresholds listed above, a trajectory analysis is performed to identify a TC track:

1) For each TC snapshot, a spatial scan is performed to see if other snapshots exist within a distance of $300 \mathrm{~km}$ during the next $6 \mathrm{~h}$.

2) If no other snapshot exists, the trajectory is regarded as having ended. In the case where multiple potential snapshots exist, if the TC center is located south of $35^{\circ} \mathrm{N}$, the closest point that is located west and poleward of the current location is chosen as belonging to the same trajectory. Otherwise, eastward/ northeastward trajectories are designated.

3) The simulated TC trajectory must last at least 3 days, and have a maximum $10-\mathrm{m}$ WSPD within $3^{\circ}$ radius of the TC center greater than $17.5 \mathrm{~m} \mathrm{~s}^{-1}$ for at least 2 days (not necessarily continuous).

4) The genesis location must be equatorward of $40^{\circ} \mathrm{N}$.

This relatively strict TC detection and tracking algorithm is used to minimize errors from tracking "TC-like" disturbances, such as tropical waves and midlatitude low pressure systems, and multiple counting for a single TC.

\section{APPENDIX C}

\section{Composite of Hurricane-Related Precipitation}

The composites of observed TC-induced precipitation are derived from the final run of GPM rainfall datasets and ERA5 atmospheric reanalysis.

The GPM is a recent constellation-based satellite mission, equipped with the first spaceborne dual-frequency precipitation radar, and a conical-scanning multichannel microwave imager. The four additional high-frequency passive microwave channels and improved algorithm (Huffman et al. 2015b,c,d) in GPM lead to significant changes in passive microwave precipitation estimates (Liu 2016) comparing to its predecessor, the Tropical Rainfall Measuring Mission (TRMM). In addition, GPM at least doubles the spatial and temporal resolution of the

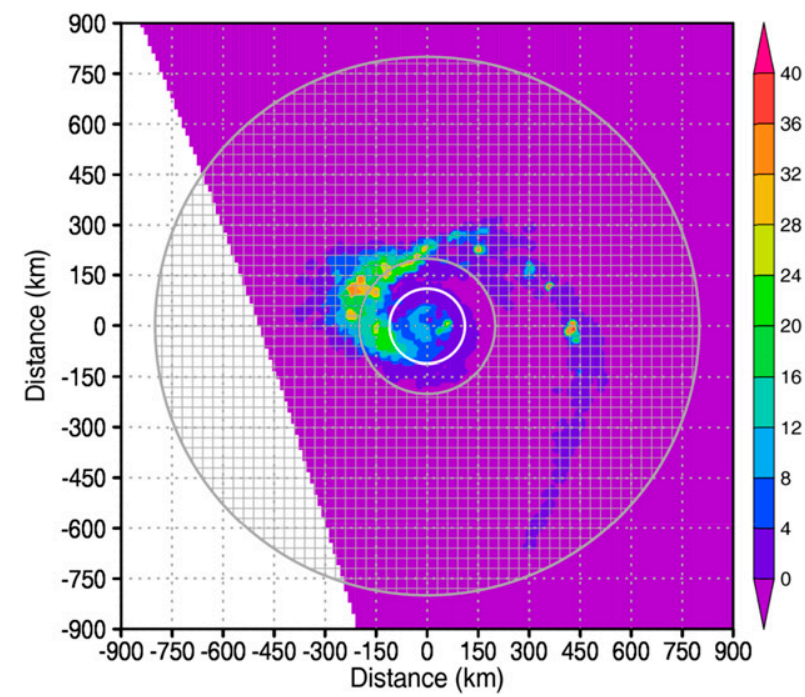

FIG. C1. An example of observed hurricane-related precipitation $\left(\mathrm{mm} \mathrm{h}^{-1}\right)$ snapshot from GPM HQ precipitation. White area indicates the area that not covered by GPM sensors. The white circle indicates the hurricane inner-core area, and the gray hatched annulus shows the area that aimed to determine the environmental vertical wind shear vector.

channels in TRMM, and yields better skill in depicting precipitation related to vortex systems, such as atmospheric TCs (Omranian et al. 2018) or oceanic eddies (Liu et al. 2018).

Although the GPM is only available after 12 March 2014, the higher spatial and temporal resolution of the GPM channels can scan TCs more frequently, which in turn largely overcomes the short temporal coverage problem. In this study, we used the passive microwave sensor (PMW) derived high-quality (HQ) precipitation from GPM final runs (latency $\sim 2.5$ months after the observation) in 1-h temporal interval and $0.1^{\circ} \times 0.1^{\circ}$ horizontal resolution to make the composites. Only TCs with greater than hurricane intensity $\left(32.9 \mathrm{~m} \mathrm{~s}^{-1}\right)$ were used. The 6-hourly observed hurricane central locations are obtained from the IBTrACS, while the hourly positions that within the 6-h IBTrACS intervals are determined by the hourly ERA5 reanalysis, in terms of the position of hurricane minimum SLP.

We defined the hurricane inner-core area as a $1^{\circ}$ radius around the hurricane center. To better resolve the precipitation within the inner core and discard the snapshots with largely missing values, we chose only the HQ precipitation snapshots with swaths covering at least $2 / 3$ of the hurricane inner core area to make the composite. Before making the composite, we also first rotated each HQ precipitation snapshot based on the corresponding environmental vertical wind shear vector, with the shear vector pointing to the top (north). The environmental vertical 
wind shear vector was defined as the ERA5 vertical shear of zonal and meridional components of winds between 200 and $850 \mathrm{hPa}$ averaged over the annulus area of 200 to $800 \mathrm{~km}$ apart from the hurricane centers, following the standard from the Statistical Hurricane Intensity Prediction Scheme (SHIPS; DeMaria et al. 2005). A schematic plot is shown in Fig. C1.

Although the temporal resolution of GPM final run is half-hourly, the observed TC central locations determined by ERA5 are only available at a 1-h interval. We also note that ERA5 is in the N320 Gaussian grid, which is approximately $0.28^{\circ} \times 0.28^{\circ}$ horizontally, while both precipitation in GPM and latitude and longitude information of observed TC central locations in IBTrACS are precise to $0.1^{\circ}$. This discrepancy in data resolution may act as one source of uncertainty in the results.

Analogous to the precipitation composite from the satellite observation, the same composite technique was also applied to the TCM hindcast simulation results.

\section{REFERENCES}

Ashok, K., S. K. Behera, S. A. Rao, H. Weng, and T. Yamagata, 2007: El Niño Modoki and its possible teleconnection. J. Geophys. Res., 112, C11007, https://doi.org/10.1029/2006JC003798.

Atlas, R., R. N. Hoffman, J. Ardizzone, S. M. Leidner, J. C. Jusem, D. K. Smith, and D. Gombos, 2011: A cross-calibrated, multiplatform ocean surface wind velocity product for meteorological and oceanographic applications. Bull. Amer. Meteor. Soc., 92, 157-174, https://doi.org/10.1175/2010BAMS2946.1.

Bacmeister, J. T., M. F. Wehner, R. B. Neale, A. Gettelman, C. Hannay, P. H. Lauritzen, J. M. Caron, and J. E. Truesdale, 2014: Exploratory high-resolution climate simulations using the Community Atmosphere Model (CAM). J. Climate, 27, 3073-3099, https://doi.org/10.1175/JCLI-D-13-00387.1.

Bell, G. D., and Coauthors, 2000: Climate assessment for 1999. Bull. Amer. Meteor. Soc., 81, S1-S50, https://doi.org/10.1175/ 1520-0477(2000)81[s1:CAF]2.0.CO;2.

Berg, W., T. L'Ecuyer, and C. Kummerow, 2006: Rainfall climate regimes: The relationship of regional TRMM rainfall biases to the environment. J. Appl. Meteor. Climatol., 45, 434-454, https://doi.org/10.1175/JAM2331.1.

Bowman, K. P., A. B. Phillips, and G. R. North, 2003: Comparison of TRMM rainfall retrievals with rain gauge data from the TAO/TRITON buoy array. Geophys. Res. Lett., 30, 1757, https://doi.org/10.1029/2003GL017552.

Bruyère, C. L., and Coauthors, 2017: Impact of climate change on Gulf of Mexico hurricanes. NCAR Tech. Note NCAR/TN535+STR, 165 pp., https://doi.org/10.5065/D6RN36J3.

Camargo, S. J., and A. H. Sobel, 2005: Western North Pacific tropical cyclone intensity and ENSO. J. Climate, 18, 29963006, https://doi.org/10.1175/JCLI3457.1.

_ K. K. Emanuel, and A. H. Sobel, 2007: Use of a genesis potential index to diagnose ENSO effects on tropical cyclone genesis. J. Climate, 20, 4819-4834, https://doi.org/10.1175/JCLI4282.1. , M. C. Wheeler, and A. H. Sobel, 2009: Diagnosis of the MJO modulation of tropical cyclogenesis using an empirical index. J. Atmos. Sci., 66, 3061-3074, https://doi.org/ 10.1175/2009JAS3101.1.
Camp, J., M. Roberts, C. MacLachlan, E. Wallace, L. Hermanson, A. Brookshaw, A. Arribas, and A. A. Scaife, 2015: Seasonal forecasting of tropical storms using the Met Office GloSea5 seasonal forecast system. Quart. J. Roy. Meteor. Soc., 141, 2206-2219, https://doi.org/10.1002/qj.2516.

Chang, P., L. Zhang, R. Saravanan, D. J. Vimont, J. C. H. Chiang, L. Ji, H. Seidel, and M. K. Tippett, 2007: Pacific meridional mode and El Niño-Southern Oscillation. Geophys. Res. Lett., 34, L16608, https://doi.org/10.1029/2007GL030302.

Chen, F., and J. Dudhia, 2001: Coupling an advanced land surfacehydrology model with the Penn State-NCAR MM5 modeling system. Part I: Model implementation and sensitivity. Mon. Wea. Rev., 129, 569-585, https://doi.org/10.1175/1520-0493(2001) $129<0569$ :CAALSH $>2.0$.CO;2.

Chen, J.-H., and S.-J. Lin, 2013: Seasonal predictions of tropical cyclones using a $25-\mathrm{km}$-resolution general circulation model. J. Climate, 26, 380-398, https://doi.org/10.1175/JCLI-D-12-00061.1.

Chen, S. S., J. A. Knaff, and F. D. Marks Jr., 2006: Effects of vertical wind shear and storm motion on tropical cyclone rainfall asymmetries deduced from TRMM. Mon. Wea. Rev., 134, 3190-3208, https://doi.org/10.1175/MWR3245.1.

Chiang, J. C. H., and D. J. Vimont, 2004: Analogous Pacific and Atlantic meridional modes of the tropical atmosphere-ocean variability. J. Climate, 17, 4143-4158, https://doi.org/10.1175/ JCLI4953.1.

Crétat, J., B. Pohl, Y. Richard, and P. Drobinski, 2012: Uncertainties in simulating regional climate of southern Africa: Sensitivity to physical parameterizations using WRF. Climate Dyn., 38, 613-634, https://doi.org/10.1007/s00382-011-1055-8.

Davis, C. A., 2018: Resolving tropical cyclone intensity in models. Geophys. Res. Lett., 45, 2082-2087, https://doi.org/10.1002/ 2017 GL076966.

Dee, D., and Coauthors, 2011: The ERA-Interim reanalysis: Configuration and performance of the data assimilation system. Quart. J. Roy. Meteor. Soc., 137, 553-597, https://doi.org/10.1002/qj.828.

DeMaria, M., M. Mainelli, L. K. Shay, J. A. Knaff, and J. Kaplan, 2005: Further improvements to the Statistical Hurricane Intensity Prediction Scheme (SHIPS). Wea. Forecasting, 20, 531-543, https://doi.org/10.1175/WAF862.1.

Donelan, M. A., B. K. Haus, N. Reul, W. J. Plant, M. Stiassnie, H. C. Graber, O. B. Brown, and E. S. Saltzman, 2004: On the limiting aerodynamic roughness of the ocean in very strong winds. Geophys. Res. Lett., 31, L18306, https://doi.org/10.1029/ 2004GL019460.

Dudhia, J., 1989: Numerical study of convection observed during the winter monsoon experiment using a mesoscale two-dimensional model. J. Atmos. Sci., 46, 3077-3107, https://doi.org/10.1175/ 1520-0469(1989)046<3077:NSOCOD>2.0.CO;2.

Emanuel, K. A., and D. S. Nolan, 2004: Tropical cyclone activity and global climate. Preprints, 26th Conf. on Hurricanes and Tropical Meteorology, Miami, FL, Amer. Meteor. Soc., 240-241.

Evans, J. P., M. Ekstrom, and F. Ji, 2012: Evaluating the performance of a WRF physics ensemble over south-east Australia. Climate Dyn., 39, 1241-1258, https://doi.org/10.1007/s00382011-1244-5.

Fu, D., P. Chang, and C. M. Patricola, 2017: Intrabasin variability of East Pacific tropical cyclones during ENSO regulated by central American gap winds. Sci. Rep., 7, 1658, https://doi.org/ 10.1038/s41598-017-01962-3.

Garratt, J. R., 1992: The Atmospheric Boundary Layer. Cambridge University Press, $316 \mathrm{pp}$.

Gray, W. M., 1984: Atlantic seasonal hurricane frequency. Part I: El Niño and $30 \mathrm{mb}$ quasi-biennial oscillation influences. Mon. 
Wea. Rev., 112, 1649-1668, https://doi.org/10.1175/15200493(1984)112<1649:ASHFPI > 2.0.CO;2.

Han, J., and H.-L. Pan, 2011: Revision of convection and vertical diffusion schemes in the NCEP Global Forecasting System. Wea. Forecasting, 26, 520-533, https://doi.org/10.1175/WAFD-10-05038.1.

Holland, G., and Coauthors, 2006: A high-resolution WRF tropical channel simulation driven by a global reanalysis. American Geophysical Union Fall Meeting, San Francisco, CA, Amer. Geophys. Union, Abstract A33F-02.

Hong, S.-Y., Y. Noh, and J. Dudhia, 2006: A new vertical diffusion package with explicit treatment of entrainment processes. Mon. Wea. Rev., 134, 2318-2341, https://doi.org/10.1175/MWR3199.1.

Hu, X., J. Nielsen-Gammon, and F. Zhang, 2010: Evaluation of three planetary boundary layer schemes in the WRF model. J. Appl. Meteor. Climatol., 49, 1831-1844, https://doi.org/ 10.1175/2010JAMC2432.1.

Huffman, G. J., and Coauthors, 2007: The TRMM Multisatellite Precipitation Analysis (TMPA): Quasi-global, multiyear, combined-sensor precipitation estimates at fine scales. J. Hydrometeor., 8, 38-55, https://doi.org/10.1175/JHM560.1.

— , and Coauthors, Eds., 2015a: The climate data guide: TRMM: Tropical Rainfall Measuring Mission. NCAR-UCAR, accessed 18 June 2015, https://climatedataguide.ucar.edu/climate-data/ trmm-tropical-rainfall-measuring-mission.

, D. T. Bolvin, D. Braithwaite, K. Hsu, R. Joyce, C. Kidd, E. J. Nelkin, and P. Xie, 2015b: NASA Global Precipitation Measurement (GPM) Integrated Multi-satellite Retrievals for GPM (IMERG). NASA Algorithm Theoretical Basis Doc., version 4.5, $26 \mathrm{pp}$., https://pmm.nasa.gov/sites/default/files/ document_files/IMERG_ATBD_V4.5.pdf.

,-- , and E. J. Nelkin, 2015c: Integrated Multi-satellite Retrievals for GPM (IMERG) technical documentation. NASA/ GSFC Code 612 Tech. Doc., 48 pp., https://pmm.nasa.gov/ sites/default/files/document_files/IMERG_doc.pdf.

$\longrightarrow,-$, and $—$, 2015d: Day 1 IMERG final run release notes. NASA Tech. Note., 9 pp., https://pmm.nasa.gov/sites/ default/files/document_files/IMERG_FinalRun_Day1_release_ notes.pdf.

Kalnay, E., and Coauthors, 1996: The NCEP/NCAR 40-Year Reanalysis Project. Bull. Amer. Meteor. Soc., 77, 437-471, https:// doi.org/10.1175/1520-0477(1996)077<0437:TNYRP>2.0.CO;2.

Katragkou, E., and Coauthors, 2015: Regional climate hindcast simulations within EURO-CORDEX: Evaluation of a WRF multi-physics ensemble. Geosci. Model Dev., 8, 603-618, https://doi.org/10.5194/gmd-8-603-2015.

Kimball, S. K., and M. S. Mulekar, 2004: A 15-year climatology of North Atlantic tropical cyclones. Part I: Size parameters. J. Climate, 17, 3555-3575, https://doi.org/10.1175/15200442(2004)017<3555:AYCONA > 2.0.CO;2.

Klotzbach, P. J., 2014: The Madden-Julian oscillation's impacts on worldwide tropical cyclone activity. J. Climate, 27, 2317-2330, https://doi.org/10.1175/JCLI-D-13-00483.1.

Knapp, K. R., M. C. Kruk, D. H. Levinson, H. J. Diamond, and C. J. Neumann, 2010: The International Best Track Archive for Climate Stewardship (IBTrACS): Unifying tropical cyclone data. Bull. Amer. Meteor. Soc., 91, 363-376, https://doi.org/ 10.1175/2009BAMS2755.1.

Knutson, T., J. Sirutis, S. Garner, I. Held, and R. E. Tuleya, 2007: Simulation of the recent multidecadal increase of Atlantic hurricane activity using an 18-km-grid regional model. Bull. Amer. Meteor. Soc., 88, 1549-1565, https://doi.org/10.1175/ BAMS-88-10-1549.
Kug, J.-S., F.-F. Jin, and S.-I. An, 2009: Two types of El Niño events: Cold tongue El Niño and warm pool El Niño. J. Climate, 22, 1499-1515, https://doi.org/10.1175/2008JCLI2624.1.

Kumar, A., Z.-Z. Hu, B. Jha, and P. Peng, 2017: Estimating ENSO predictability based on multi-model hindcasts. Climate Dyn., 48, 39-51, https://doi.org/10.1007/s00382-016-3060-4.

Lee, C.-Y., S. J. Camargo, F. Vitart, A. H. Sobel, and M. K. Tippett, 2018: Sub-seasonal tropical cyclone genesis prediction and MJO in the S2S dataset. Wea. Forecasting, 33, 967-988, https:// doi.org/10.1175/WAF-D-17-0165.1.

Leung, L., and Coauthors, 2006: Analysis and evaluation of WRF tropical channel simulations. Proc. 2006 American Geophysical Union Joint Assembly, Baltimore, MD, Amer. Geophys. Union, Abstract A43G-05.

Li, R., J. Jin, S.-Y. Wang, and R. R. Gillies, 2014: Significant impacts of radiation physics in the WRF model on the precipitation and dynamics of the West African monsoon. Plants, Soils, and Climate Faculty Publication 737, 32 pp., https:// digitalcommons.usu.edu/psc_facpub/737.

Liao, L., and R. Meneghini, 2009: Validation of TRMM precipitation radar through comparison of its multiyear measurements with ground-based radar. J. Appl. Meteor. Climatol., $\mathbf{4 8}$, 804-817, https://doi.org/10.1175/2008JAMC1974.1.

Liebmann, B., and C. A. Smith, 1996: Description of a complete (interpolated) outgoing longwave radiation dataset. Bull. Amer. Meteor. Soc., 77, 1275-1277.

Lin, Y.-L., R. D. Farley, and H. D. Orville, 1983: Bulk parameterization of the snow field in a cloud model. J. Climate Appl. Meteor., 22, 1065-1092, https://doi.org/10.1175/15200450(1983)022<1065:BPOTSF $>2.0 . \mathrm{CO} ; 2$.

Liu, X., P. Chang, J. Kurian, R. Saravanan, and X. Lin, 2018: Satellite-observed precipitation response to ocean mesoscale eddies. J. Climate, 31, 6879-6895, https://doi.org/10.1175/ JCLI-D-17-0668.1.

Liu, Z., 2016: Comparison of Integrated Multisatellite Retrievals for GPM (IMERG) and TRMM Multisatellite Precipitation Analysis (TMPA) monthly precipitation products: Initial results. J. Hydrometeor., 17, 777-790, https://doi.org/10.1175/ JHM-D-15-0068.1.

Lonfat, M., F. D. Marks Jr., and S. S. Chen, 2004: Precipitation distribution in tropical cyclones using the Tropical Rainfall Measuring Mission (TRMM) microwave imager: A global perspective. Mon. Wea. Rev., 132, 1645-1660, https://doi.org/ 10.1175/1520-0493(2004)132<1645:PDITCU $>2.0 . C O ; 2$.

Maloney, E. D., and D. L. Hartmann, 2000a: Modulation of eastern North Pacific hurricanes by the Madden-Julian oscillation. J. Climate, 13, 1451-1460, https://doi.org/10.1175/15200442(2000)013<1451:MOENPH > 2.0.CO;2.

$\longrightarrow$, and 2000b: Modulation of hurricane activity in the Gulf of Mexico by the Madden-Julian oscillation. Science, 287, 2002-2004, https://doi.org/10.1126/science.287.5460.2002.

Mapes, B., S. Tulich, T. Nasuno, and M. Satoh, 2008: Predictability aspects of global aqua-planet simulations with explicit convection. J. Meteor. Soc. Japan, 86A, 175-185, https:// doi.org/10.2151/jmsj.86A.175.

Mlawer, E. J., S. J. Taubman, P. D. Brown, M. J. Iacono, and S. A. Clough, 1997: Radiative transfer for inhomogeneous atmosphere: RRTM, a validated correlated-k model for the longwave. J. Geophys. Res., 102, 16663-16682, https://doi.org/10.1029/97JD00237.

Monin, A. S., and A. M. Obukhov, 1954: Osnovnye zakonomernosti turbulentnogo peremeshivanija $\mathrm{v}$ prizemnom sloe atmosfery (Basic laws of turbulent mixing in the atmosphere near the ground). Tr. Akad. Nauk SSSR Geofiz. Inst., 24, 163-187. 
Murakami, H., B. Wang, and A. Kitoh, 2011: Future change of western North Pacific typhoons: Projections by a $20-\mathrm{km}-\mathrm{mesh}$ global atmospheric model. J. Climate, 24, 1154-1169, https:// doi.org/10.1175/2010JCLI3723.1.

- and Coauthors, 2012: Future changes in tropical cyclone activity projected by the new high-resolution MRI-AGCM. J. Climate, 25, 3237-3260, https://doi.org/10.1175/JCLI-D-11-00415.1.

_- and Coauthors, 2015: Simulation and prediction of category 4 and 5 hurricanes in the high-resolution GFDL HiFLOR coupled climate model. J. Climate, 28, 9058-9079, https://doi.org/ 10.1175/JCLI-D-15-0216.1.

Nakano, M., M. Sawada, T. Nasuno, and M. Satoh, 2015: Intraseasonal variability and tropical cyclogenesis in the western North Pacific simulated by a global nonhydrostatic atmospheric model. Geophys. Res. Lett., 42, 565-571, https:// doi.org/10.1002/2014GL062479.

Nasrollahi, N., A. AghaKouchak, J. Li, X. Gao, K. Hsu, and S. Sorooshian, 2012: Assessing the impacts of different WRF precipitation physics in hurricane simulations. Wea. Forecasting, 27, 1003-1016, https://doi.org/10.1175/WAF-D-10-05000.1.

Omranian, E., H. O. Sharif, and A. A. Tavakoly, 2018: How well can global precipitation measurement (GPM) capture hurricanes? Case study: Hurricane Harvey. Remote Sens., 10, 1150, https://doi.org/10.3390/rs10071150.

Patricola, C. M., R. Saravanan, and P. Chang, 2014: The impact of the El Niño-Southern Oscillation and Atlantic meridional mode on seasonal Atlantic tropical cyclone activity. J. Climate, 27, 5311-5328, https://doi.org/10.1175/JCLI-D-13-00687.1.

_ P. Chang, and R. Saravanan, 2016: Degree of simulated suppression of Atlantic tropical cyclones modulated by flavour of El Niño. Nat. Geosci., 9, 155-160, https://doi.org/10.1038/ngeo2624.

_- R. Saravanan, and P. Chang, 2017: A teleconnection between Atlantic sea surface temperature and eastern and central North Pacific tropical cyclones. Geophys. Res. Lett., 44, 11671174, https://doi.org/10.1002/2016GL071965.

_ S. J. Camargo, P. J. Klotzbach, R. Saravanan, and P. Chang, 2018: The influence of ENSO flavors on western North Pacific tropical cyclone activity. J. Climate, 31, 5395-5416, https:// doi.org/10.1175/JCLI-D-17-0678.1.

Ray, P., C. Zhang, J. Dudhia, and S. S. Chen, 2009: A numerical case study on the initiation of the Madden-Julian oscillation. J. Atmos. Sci., 66, 310-331, https://doi.org/10.1175/2008JAS2701.1.

,,,--- T. Li, and M. W. Moncrieff, 2012: Tropical channel model. Climate Models, L. M. Druyan, Ed., InTech, 3-18.

Roberts, D. P., and R. J. Pasch, 2018: The 2017 eastern North Pacific hurricane season: A quiet year. Weatherwise, 71, 38-44, https://doi.org/10.1080/00431672.2018.1448149.

Saha, S., and Coauthors, 2010: The NCEP Climate Forecast System Reanalysis. Bull. Amer. Meteor. Soc., 91, 1015-1057, https:// doi.org/10.1175/2010BAMS3001.1.

— , and Coauthors, 2014: The NCEP Climate Forecast System version 2. J. Climate, 27, 2185-2208, https://doi.org/10.1175/ JCLI-D-12-00823.1.

Satoh, M., and Coauthors, 2012: The intra-seasonal oscillation and its control of tropical cyclones simulated by high-resolution global atmospheric models. Climate Dyn., 39, 2185-2206, https://doi.org/10.1007/s00382-011-1235-6.

Shaevitz, D. A., and Coauthors, 2014: Characteristics of tropical cyclones in high-resolution models of the present climate. J. Adv. Model. Earth Syst., 6, 1154-1172, https://doi.org/ 10.1002/2014MS000372.

Skamarock, W. C., and Coauthors, 2008: A description of the Advanced Research WRF version 3. NCAR Tech. Note
NCAR/TN-475+STR, 113 pp., https://doi.org/10.5065/ D68S4MVH.

Taylor, K., 2001: Summarizing multiple aspects of model performance in a single diagram. J. Geophys. Res., 106, 7183-7192, https://doi.org/10.1029/2000JD900719.

Vecchi, G. A., and Coauthors, 2014: On the seasonal forecasting of regional tropical cyclone activity. J. Climate, 27, 7994-8016, https://doi.org/10.1175/JCLI-D-14-00158.1.

Vitart, F., and Coauthors, 2017: The Subseasonal to Seasonal (S2S) Prediction Project Database. Bull. Amer. Meteor. Soc., 98, 163-173, https://doi.org/10.1175/BAMS-D-16-0017.1.

Waliser, D. E., and Coauthors, 2012: The "year" of tropical convection (May 2008-April 2010): Climate variability and weather highlights. Bull. Amer. Meteor. Soc., 93, 1189-1218, https://doi.org/10.1175/2011BAMS3095.1.

Walsh, K. J. E., and Coauthors, 2015: Hurricanes and climate: The U.S. CLIVAR Working Group on hurricanes. Bull. Amer. Meteor. Soc., 96, 997-1017, https://doi.org/10.1175/BAMS-D13-00242.1.

Wang, B., and J. C. L. Chan, 2002: How strong ENSO events affect tropical storm activity over the western North Pacific. J. Climate, 15, 1643-1658, https://doi.org/10.1175/1520-0442(2002)015<1643: HSEEAT > 2.0.CO;2.

Wehner, M. F., and Coauthors, 2014: The effect of horizontal resolution on simulation quality in the Community Atmospheric Model, CAM5.1. J. Adv. Model. Earth Syst., 6, 980997, https://doi.org/10.1002/2013MS000276.

Wheeler, M., and G. N. Kiladis, 1999: Convectively coupled equatorial waves: Analysis of clouds and temperature in the wavenumberfrequency domain. J. Atmos. Sci., 56, 374-399, https://doi.org/ 10.1175/1520-0469(1999)056<0374:CCEWAO >2.0.CO;2.

- and H. H. Hendon, 2004: An all-season real-time multivariate MJO index: Development of an index for monitoring and prediction. Mon. Wea. Rev., 132, 1917-1932, https://doi.org/ 10.1175/1520-0493(2004)132<1917:AARMMI > 2.0.CO;2.

Wu, L., Z. Wen, R. Huang, and R. Wu, 2012: Possible linkage between the monsoon trough variability and the tropical cyclone activity over the western North Pacific. Mon. Wea. Rev., 140, 140-150, https://doi.org/10.1175/MWR-D-11-00078.1.

Xiang, B., and Coauthors, 2015: Beyond weather time-scale prediction for Hurricane Sandy and Super Typhoon Haiyan in a global climate model. Mon. Wea. Rev., 143, 524-535, https:// doi.org/10.1175/MWR-D-14-00227.1.

Yu, L., X. Jin, and R. A. Weller, 2008: Multidecade Global Flux Datasets from the Objectively Analyzed Air-Sea Fluxes (OAFlux) Project: Latent and sensible heat fluxes, ocean evaporation, and related surface meteorological variables. Woods Hole Oceanographic Institution, OAFlux Project Tech. Rep. OA-2008-01, 64 pp.

Zhang, G., Z. Wang, T. J. Dunkerton, M. S. Peng, and G. Magnusdottir, 2016: Extratropical impacts on Atlantic tropical cyclone activity. J. Atmos. Sci., 73, 1401-1418, https:// doi.org/10.1175/JAS-D-15-0154.1.

,-- M. S. Peng, and G. Magnusdottir, 2017: Characteristics and impacts of extratropical Rossby wave breaking during the Atlantic hurricane season. J. Climate, 30, 2363-2379, https:// doi.org/10.1175/JCLI-D-16-0425.1.

Zhao, M., I. M. Held, S.-J. Lin, and G. A. Vecchi, 2009: Simulations of global hurricane climatology, interannual variability, and response to global warming using a $50-\mathrm{km}$ resolution GCM. J. Climate, 22, 6653-6678, https://doi.org/10.1175/ 2009JCLI3049.1. 